\title{
Understanding the electrocatalysis of oxygen reduction on platinum and its alloys
}

Stephens, Ifan E. L.; Bondarenko, Alexander S.; Grønbjerg, Ulrik; Vej-Hansen, Ulrik Grønbjerg; Rossmeisl, Jan; Chorkendorff, Ib

Published in:

Energy \& Environmental Science

Link to article, DOI:

10.1039/c2ee03590a

Publication date:

2012

Document Version

Publisher's PDF, also known as Version of record

Link back to DTU Orbit

Citation (APA):

Stephens, I. E. L., Bondarenko, A. S., Grønbjerg, U., Vej-Hansen, U. G., Rossmeisl, J., \& Chorkendorff, I. (2012). Understanding the electrocatalysis of oxygen reduction on platinum and its alloys. Energy \& Environmental Science, 5(5), 6744-6762. https://doi.org/10.1039/c2ee03590a

\section{General rights}

Copyright and moral rights for the publications made accessible in the public portal are retained by the authors and/or other copyright owners and it is a condition of accessing publications that users recognise and abide by the legal requirements associated with these rights.

- Users may download and print one copy of any publication from the public portal for the purpose of private study or research.

- You may not further distribute the material or use it for any profit-making activity or commercial gain

- You may freely distribute the URL identifying the publication in the public portal 


\title{
Environmental Science
}

\author{
Cite this: Energy Environ. Sci., 2012, 5, 6744
}

www.rsc.org/ees

PERSPECTIVE

\section{Understanding the electrocatalysis of oxygen reduction on platinum and its alloys}

\author{
Ifan E. L. Stephens, ${ }^{a}$ Alexander S. Bondarenko, ${ }^{a b}$ Ulrik Grønbjerg, ${ }^{a}$ Jan Rossmeisl ${ }^{c}$ and Ib Chorkendorff ${ }^{* a}$ \\ Received 30th December 2011, Accepted 24th February 2012 \\ DOI: 10.1039/c2ee03590a
}

\begin{abstract}
The high cost of low temperature fuel cells is to a large part dictated by the high loading of Pt required to catalyse the oxygen reduction reaction (ORR). Arguably the most viable route to decrease the $\mathrm{Pt}$ loading, and to hence commercialise these devices, is to improve the ORR activity of Pt by alloying it with other metals. In this perspective paper we provide an overview of the fundamentals underlying the reduction of oxygen on platinum and its alloys. We also report the ORR activity of $\mathrm{Pt}_{5} \mathrm{La}$ for the first time, which shows a 3.5- to 4.5 -fold improvement in activity over $P t$ in the range 0.9 to $0.87 \mathrm{~V}$, respectively. We employ angle resolved X-ray photoelectron spectroscopy and density functional theory calculations to understand the activity of $\mathrm{Pt}_{5} \mathrm{La}$.
\end{abstract}

\section{Introduction}

At present, the production of polymer electrolyte membrane fuel cells (PEMFCs) requires relatively high loadings of platinum, which is both expensive and scarce. A state-of-the-art fuel cell requires $0.5 \mathrm{mg}$ Pt per $\mathrm{cm}^{2}$ electrode area. ${ }^{1}$ This results in $\sim 0.5 \mathrm{~g}$ Pt per $\mathrm{kW}$ of power, or $50 \mathrm{~g}$ Pt per $100 \mathrm{~kW}$ vehicle. At present, around 200 tons of Pt are being produced each year, globally. ${ }^{2}$ Should the total annual production of $\mathrm{Pt}$ be dedicated entirely to the production of PEMFC-powered automotives, using current technology, only 4 million cars could be produced. The current output of the automobile industry is at least an order of magnitude larger than this. Therefore, for PEMFCs to become economically viable, catalyst costs need to be reduced to a similar level as those of the platinum group metals used in catalytic

${ }^{a}$ Center for Individual Nanoparticle Functionality, Department of Physics, Building 312, Technical University of Denmark (DTU), DK-2800 Lyngby, Denmark. E-mail: ibchork@fysik.dtu.dk

${ }^{b}$ Current address: Center for Electrochemical Sciences Ruhr Universitaet Bochum, Universitaetsstr. 150 NC 4/73, 44780 Bochum, Germany

${ }^{c}$ Center for Atomic-Scale Materials Design, Department of Physics, Building 307, Technical University of Denmark (DTU), DK-2800 Lyngby, Denmark converters for internal combustion engines. $\uparrow$ The anode loading could be dropped to $0.05 \mathrm{mg} \mathrm{cm} \mathrm{cm}^{-2}$ without measurable kinetic losses. ${ }^{5}$ However, $0.4 \mathrm{mg} \mathrm{cm}{ }^{-2}$ is currently needed at the cathode, ${ }^{6,7}$ where the oxygen reduction reaction (ORR) takes place:

$$
\mathrm{O}_{2}+4 \mathrm{H}^{+}+4 \mathrm{e}^{-} \rightarrow 2 \mathrm{H}_{2} \mathrm{O}
$$

The measured polarisation of a state-of-the-art Pt-based PEMFC is shown in the red curve in Fig. $1 .^{7}$ At the highest current density, $1.5 \mathrm{~A} \mathrm{~cm}^{-2}$, the working potential is $0.57 \mathrm{~V}$, constituting a significant drop, or overpotential, $\eta$, from the theoretical thermodynamic limit, $U_{0}$, of $1.17 \mathrm{~V}$. The blue squares represent the contribution to the overpotential from the ORR, $\eta_{\mathrm{ORR}}$, i.e. eliminating the overpotential from transport

\footnotetext{
$\uparrow$ We estimate the average autocatalyst loading in motor vehicles to be $\sim 3.4 \mathrm{~g}$, obtained by dividing the total amount of platinum group metals used for autocatalysts by the global production of motor vehicles in 2010 , i.e. $\left(2.66 \times 10^{8}\right) /\left(77.9 \times 10^{6}\right)^{2,3}$ The loading is dependent on the type of vehicle, and can vary between $1 \mathrm{~g}$ and $15 \mathrm{~g}^{4}{ }^{4}$
}

\section{Broader context}

Low temperature fuel cells hold promise as an emission-free source of power, particularly attractive for automotives. In order for them to replace the internal combustion engines currently used today, significant decrease in their cost is required. A large part of their current high cost can be traced back to the platinum catalysts used to drive the oxygen reduction reaction. Consequently, a large body of academic and industrial research has been devoted towards improving the sluggish kinetics of this reaction. Arguably, the most viable means to achieve this would be to improve the oxygen reduction activity of platinum by alloying it with other metals. Such an alloy would need to be both active and stable. In this perspective, we review the fundamental challenges in relation to the electrocatalysis of the oxygen reduction reaction on platinum and its alloys. 
limitations or hydrogen oxidation. It is clear that the ORR is the main obstacle, as it is responsible for roughly two thirds of the overpotential. Naturally, substantial efforts are being devoted towards improving the performance of ORR catalysts beyond the current state of the art. ${ }^{6-8}$ A more active catalyst would have a higher current density at a given potential. It follows that such a catalyst could be used to reduce the energy losses or decrease the precious metal loading. Ideally, one could do away with $\mathrm{Pt}$ altogether, and use catalysts made from more abundant

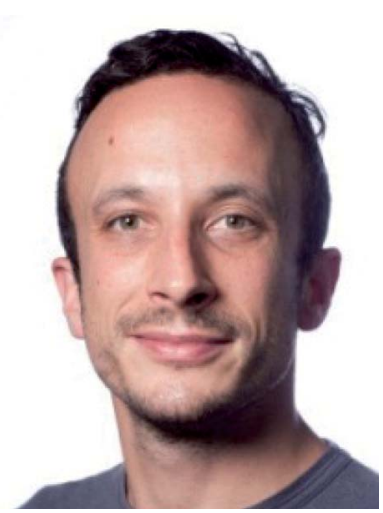

Ifan E.L. Stephens

Ifan Stephens obtained his PhD from the University of Cambridge. Since 2008 he has been employed at the Center for Individual Nanoparticle Functionality (CINF) at the Technical University of Denmark (DTU), first as a postdoctoral researcher, and since January 2010 as an Assistant Professor. His research is concerned with the use of electrocatalysis for fuel cells and sustainable fuel production. He is particularly interested in the interplay between electrochemical experiments, first principle calculations and surface science methods in the search for new catalyst materials.

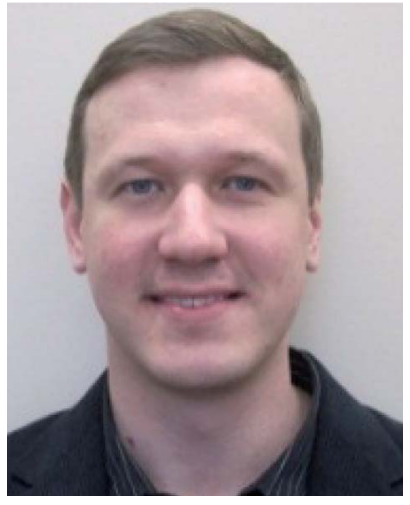

Alexander S. Bondarenko

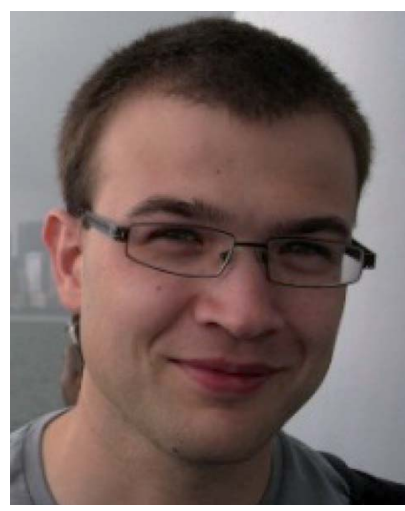

Ulrik Grønbjerg
Alexander S. Bondarenko is a Junior Group Leader at RuhrUniversität Bochum, Germany. He obtained his PhD in Chemistry from the Belarusian State University in 2005. His research focuses on electrocatalysis, adsorption phenomena at the electrode surface, and developing methods for detailed in situ characterisation of the electrode-electrolyte interface.

Ulrik Grønbjerg is a graduate student in Physics and Nanotechnology with the Center for Individual Nanoparticle Functionality at the Department of Physics, the Technical University of Denmark. His research is focused on the interplay between environment, structure and functionality of nanoparticles and surfaces, investigated using theoretical methods, such as electronic structure calculations.

elements. However, the acidic and oxidising environment of a PEMFC places severe constraints upon the choice of materials that can be deployed: even Pt corrodes at $\sim 1$ V. ${ }^{11,12}$ Apart from $\mathrm{Pt}$, only $\mathrm{Au}$ and $\mathrm{Ir}$ are thermodynamically stable in the bulk metallic form at potentials greater than $0.9 \mathrm{~V} .{ }^{13}$ There are notable examples whereby non-precious metals have been stabilised in non-metallic forms, such as metalorganic complexes, ${ }^{14,15}$ enzymes, ${ }^{16,17}$ oxides ${ }^{18,19}$ or $\mathrm{N}$-functionalised graphene-based materials. ${ }^{20-22}$ Although they can exhibit activity close to or even better than that of $\mathrm{Pt}$, they often suffer from poor stability (especially in acidic solutions), or a low density of active sites.

Given the above challenges, most research efforts in relation to ORR catalysis are focussed upon improving the activity of Pt. ${ }^{7,23-30}$ This is achieved by forming a structure with a Pt overlayer on a core with a different composition. Typically, the core consists of $\mathrm{Pt}$ alloyed with a less noble late transition $3 \mathrm{~d}$ metal such as $\mathrm{Fe}, \mathrm{Co}, \mathrm{Ni}$, and $\mathrm{Cu}$, although it might contain other

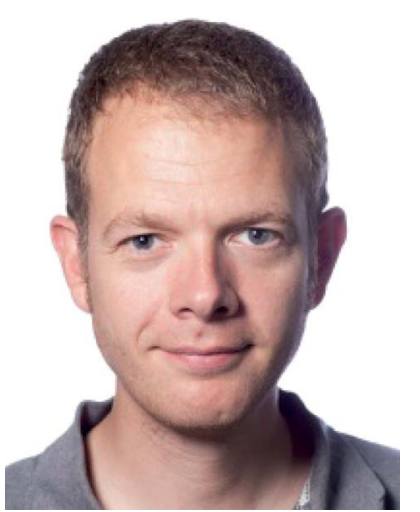

Jan Rossmeisl

Since 2009 Jan Rossmeisl has been an Associate Professor at the Department of Physics at DTU. He heads the Theoretical Electrochemistry Group, part of the Center for Atomic scale Materials Design. Rossmeisl received a PhD in solid state physics from DTU in 2004. He is the author or co-author of around 50 peer-reviewed scientific articles and has mentored approximately 18 postdoctoral fellows and graduate students. His research interests include: density functional theory simulations, photocatalysis and electrocatalysis for energy conversion, modeling of charged interfaces and charge transfer reactions, and material design of catalysis of the oxygen reduction/evolution and hydrogen evolution/oxidation reactions.

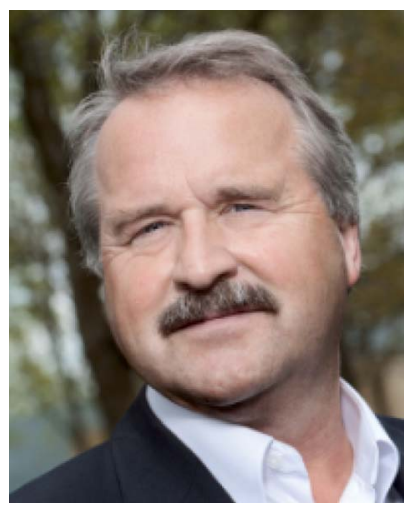

Ib Chorkendorff
Professor Ib Chorkendorff obtained his PhD in 1985 in experimental surface science from Odense University, Denmark. After working as a postdoc with Prof. John T. Yates Jr at University of Pittsburgh, USA, he was employed in 1987 at DTU to establish an experimental activity within surface physics, investigating fundamental aspects of heterogeneous catalysis. In 2005 he established CINF, broadening his activities to include technologies for producing solar fuels utilizing electrocatalysis and photocatalysis to find new and effective materials for improving sustainable energy conversion and environmental protection. 
platinum group metals such as $\mathrm{Pd}$ or Au. The Pt overlayer provides kinetic stability against the dissolution of the less noble solute component. At the same time, the electronic structure of the Pt surface is modified by the underlying alloy, resulting in improved ORR activity. ${ }^{26}$

Most often, catalysts for fuel cells are supported on a highsurface area carbon based support. This is shown in the tomographic reconstruction of transmission electron microscopy (TEM) images in Fig. 2a of $\mathrm{PtCr}$ alloy nanoparticles supported on $\mathrm{C}$, denoted as $\mathrm{PtCr} / \mathrm{C}$. Fig. $2 \mathrm{~b}$ is also based on a reconstruction of TEM images, and depicts an atomically resolved individual $\mathrm{Pt}$ nanoparticle, showing ordered facets, including terraces, steps and kink sites.

The use of Pt alloys as ORR catalysts is not particularly new; alloys such as $\mathrm{Pt}_{x} \mathrm{Ti}$ or $\mathrm{Pt}_{x} \mathrm{Cr}$ were used in the cathodes of phosphoric acid fuel cells over 30 years ago. ${ }^{31-33}$ Building upon this, in the 1990s, researchers started to implement $\mathrm{Pt}_{x} \mathrm{Ni}_{1} \mathrm{Pt}_{x} \mathrm{Co}$ and $\mathrm{Pt}_{x} \mathrm{Cr}$ in PEMFCs, reporting significant improvement in activity over pure Pt catalysts. ${ }^{30,34-36}$ During the 2000 s, research in the field increased, ${ }^{7,37}$ as governments and industry showed

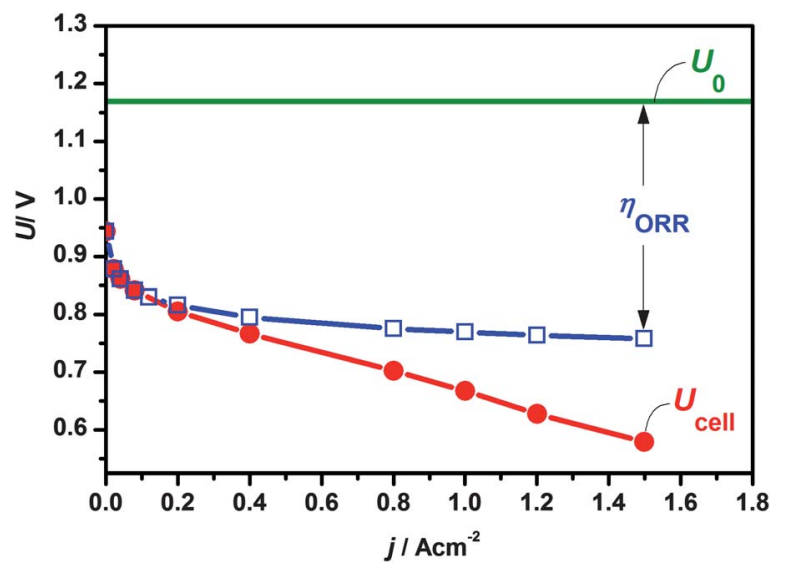

Fig. 1 Polarisation curve of a state-of-the art fuel cell. Operated at 80 ${ }^{\circ} \mathrm{C}$, at a total pressure of $150 \mathrm{kPa} \mathrm{H} / \mathrm{O}_{2}$, adapted from Gasteiger et al. ${ }^{7}$
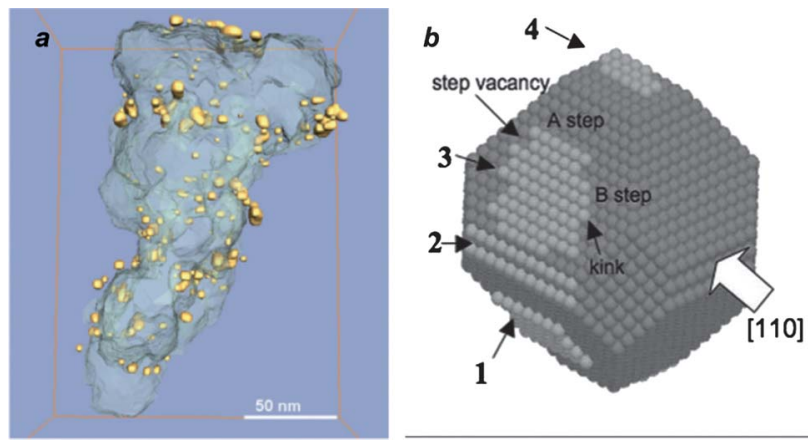

Fig. 2 (a) Tomographic reconstruction of $\mathrm{PtCr} / \mathrm{C}$, catalyst nanoparticles based on a series of high-angle annular dark-field scanning transmission electron microscopy (TEM) images. The carbon support is shown in grey, whereas the nanoparticles are shown in yellow. Copyright 2008 Wiley, reproduced with permission from Gontard et al. ${ }^{9}$ (b) Atomically resolved, fitted model of a $6 \mathrm{~nm}$ Pt nanoparticle, based on a series of sphericalaberration-corrected TEM images. Copyright 2007 Wiley, reproduced with permission from Gontard et al. ${ }^{10}$ increased interest in the development of PEMFCs for powering automotives. $^{38}$

In their widely cited review paper from 2005, Gasteiger et al. quantified the improvements required to the activity of $\mathrm{Pt}$ to enable the commercialisation of automotives running on PEMFCs. ${ }^{7}$ According to their measurements, state-of-the-art carbon-supported pure Pt nanoparticles exhibited a mass activity of $0.16 \mathrm{~A} \mathrm{mg}_{\mathrm{Pt}^{-1}}$ at $U=0.9 \mathrm{~V}$ with respect to a reversible hydrogen electrode (RHE) \& They predicted that a two- to four-fold improvement in mass activity over pure $\mathrm{Pt}$ would be sufficient. However, their estimation did not take into account the effect of increased Pt consumption from PEMFC production on the supply of Pt. $\S$ Making provisions for supply constraints, the same authors have revised this quantity and suggest that a 4-10-fold improvement in ORR activity over pure $\mathrm{Pt}$ would be necessary. ${ }^{1,6,23}$

In this perspective article, we review the current understanding of the ORR on Pt and its alloys, providing selected examples from the literature. We focus specifically on the factors governing the stability and activity of these materials, and make several suggestions for future directions in the field.

We also discuss the recent progress at our own laboratory related to the development of alloys of $\mathrm{Pt}$ and early transition metals as oxygen reduction catalysts. ${ }^{28,41} \mathrm{Pt}_{3} \mathrm{Y}$ is particularly promising: it has a very high activity, and its negative alloying energy could stabilise it sufficiently to minimise catalyst degradation under the operating conditions of a PEMFC. ${ }^{28}$

\section{Theoretical trends in activity for $\mathbf{P t}$ and its alloys}

The ORR consists of four proton transfers and four electron transfers to each $\mathrm{O}_{2}$ molecule $\left(\mathrm{O}_{2}+4 \mathrm{H}^{+}+4 \mathrm{e}^{-} \rightarrow 2 \mathrm{H}_{2} \mathrm{O}\right)$ and several different intermediates, including $\mathrm{O}^{*}, \mathrm{HO}^{*}$ and $\mathrm{HOO}^{*}$ (where $\mathrm{O}^{*}, \mathrm{HO}^{*}$ and $\mathrm{HOO}^{*}$ are oxygen, hydroxyl, and superhydroxyl groups adsorbed onto active sites). The experimental elucidation of the reaction mechanism is challenging (and often controversial), in particular as the intermediates cannot be easily probed in situ. ${ }^{42,43}$

The theoretical modelling of electrochemical reactions is equally complex, as it needs to account for the effect of the solvent on the adsorbed intermediates, the highly charged electric field in the double layer, the free energy of the electrons in the solid and the free energy of the solvated reactants as a function of potential. ${ }^{44-54}$ However, it turns out that the overall trends can be

\# We note that a fuel cell would probably be operated at potentials lower than $0.9 \mathrm{~V}$, to maximise the power output. However, catalysts are typically benchmarked at $0.9 \mathrm{~V}$ to minimise artefacts from the measurements. ${ }^{7}$ At lower potentials there would be a significant influence from the Ohmic drop or the transport of $\mathrm{O}_{2}$, whereas at higher potentials there would be a significant effect from capacitative currents (in rotating disk experiments) or $\mathrm{H}_{2}$ crossover (in a fuel cell stack).

$\S$ Since 1992, the demand for Pt has consistently outstripped the supply, except in 2009 and 2011. This shortfall in supply has been offset by consuming Pt stocks from inventories. This explains the increase in its price from around $\$ 10$ per $\mathrm{g}$ in 1992 to $\$ 60$ per $\mathrm{g}$ today. ${ }^{2,39}$ Approximately $75 \%$ of this Pt comes from the Bushveld Complex in South Africa. This makes the price of Pt particularly volatile in the event of any unexpected constraints to the supply, as evidenced by the effects of a two week power outage in South Africa in $2008 .{ }^{39}$ An annual production of 0.5 million fuel cell cars using present technology would severely exacerbate the price of Pt. ${ }^{40}$ 


\section{a. Free Energy Diagram for $\mathrm{Pt}_{3} \mathbf{Y}$ (111)}

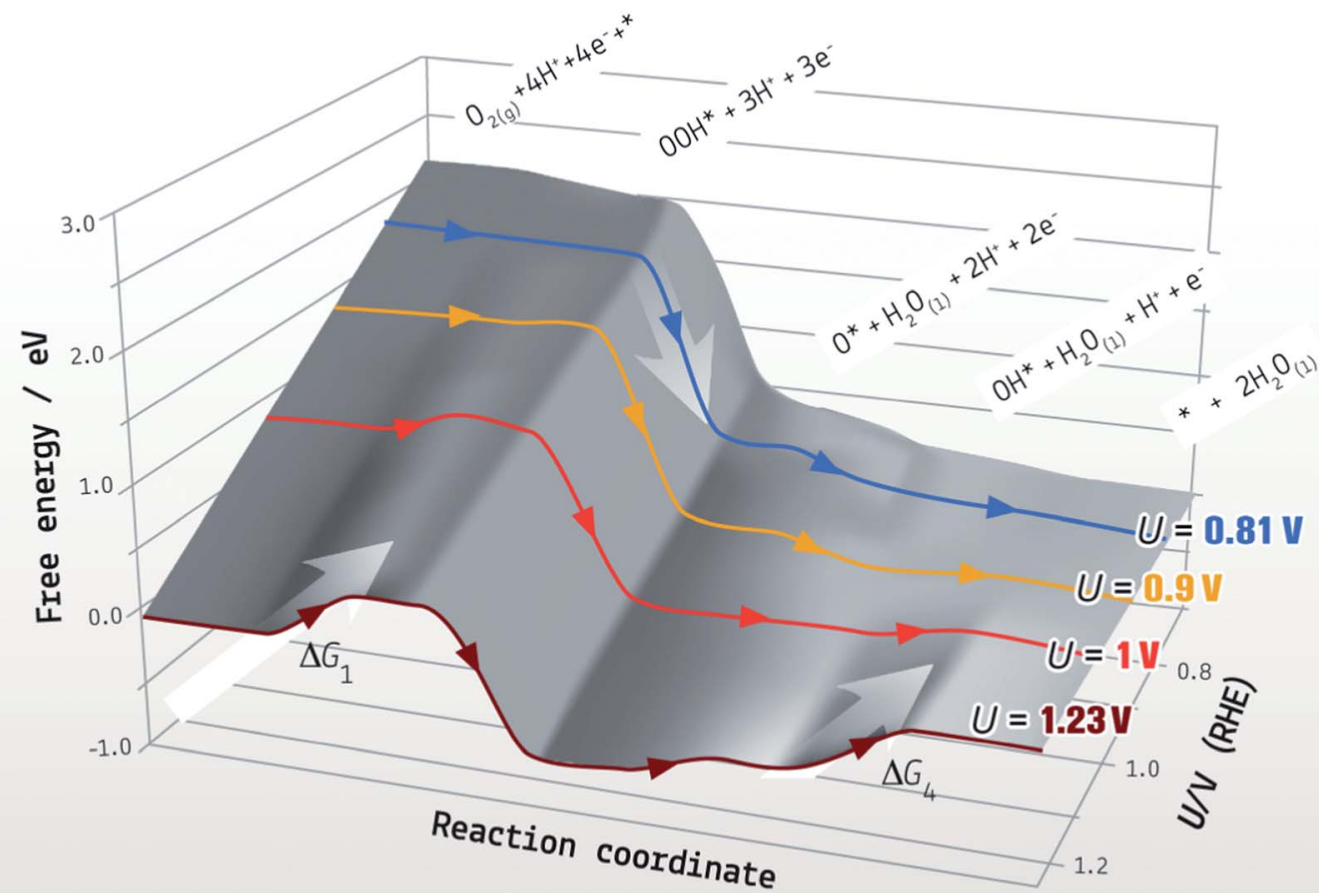

b. Cyclic voltammogram in $\mathrm{O}_{2}$ for polycrystalline $\mathrm{Pt}_{3} \mathrm{Y}$
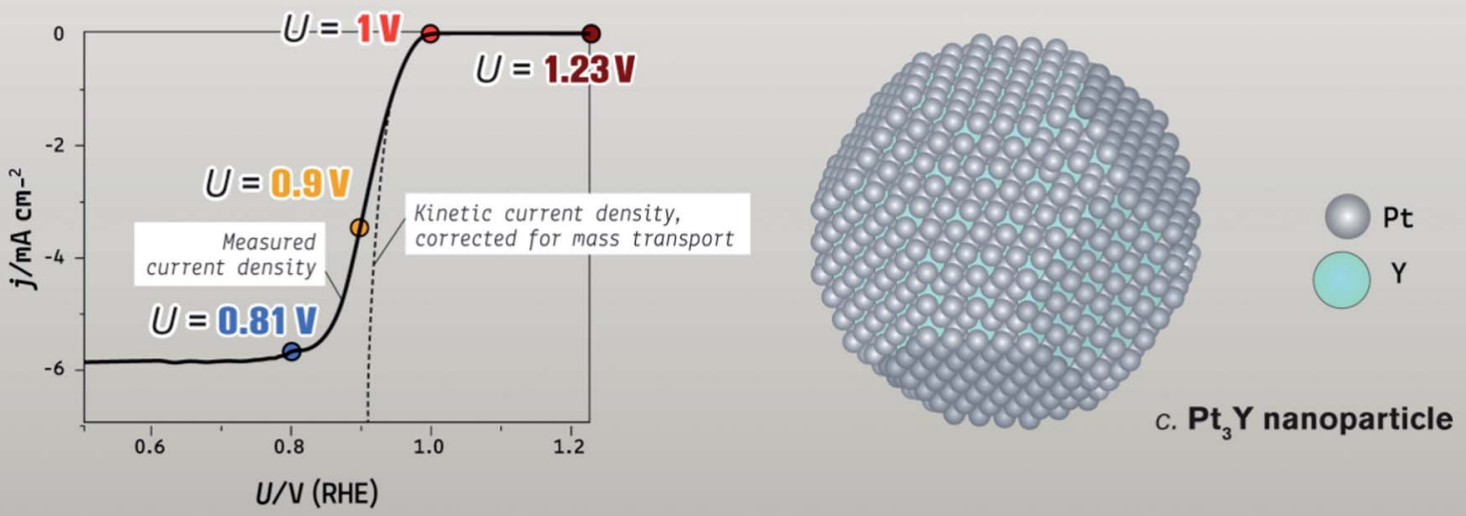

Fig. 3 (a) Theoretical free energy diagram for $\mathrm{Pt}_{3} \mathrm{Y}(111)$ with $25 \% \mathrm{Y}$ in the subsurface layer and $1 / 4$ ML O pre-adsorbed, from DFT, (b) experimental cyclic voltammogram in $\mathrm{O}_{2}$-saturated $0.1 \mathrm{M} \mathrm{HClO}_{4}$ for polycrystalline $\mathrm{Pt}_{3} \mathrm{Y}$ at $23{ }^{\circ} \mathrm{C}$ (anodic sweep only), and (c) an illustration of a $\mathrm{Pt}_{3} \mathrm{Y}$ nanoparticle. All data are from Greeley et al. ${ }^{28}$

obtained within a somewhat simpler framework by linking to the gas phase. ${ }^{55}$ Catalytic reactions at the gas-solid interface are more straightforward to calculate; density functional theory (DFT) provides accurate values for the chemical potential of gas phase species. ${ }^{56-59}$ By definition, when the electrode potential $U=$ $0 \mathrm{~V}$ with respect to a standard hydrogen electrode (SHE), the hydrogen evolution and oxidation reactions are at equilibrium: $2 \mathrm{H}^{+}+2 \mathrm{e}^{-} \rightleftharpoons \mathrm{H}_{2}$. Therefore, at $U=0 \mathrm{~V}$ (RHE), the free energies of the solvated protons and the electrons in the solid are equal to the free energy of gas phase hydrogen at atmospheric pressure. Consequently, at $0 \mathrm{~V}$, the adsorption energy of any species in equilibrium with gas phase hydrogen is equal to that of an electrochemically formed species in equilibrium with protons and electrons, providing that a small correction is made (if necessary) for the effect of the electric field and water. Changing the electrode potential results in a $1: 1$ shift in the free energy of the electrons. ${ }^{55,60,61}$

By taking into consideration the adsorption energies of the different intermediates in the ORR, including $\mathrm{O}^{*}, \mathrm{HO}^{*}$, and $\mathrm{HOO}^{*}$, it then becomes possible to calculate the overall free energy pathway for the reaction, as a function of potential. This is shown schematically in Fig. 3a for $\mathrm{Pt}_{3} \mathrm{Y}(111)$, along with the experimental measurement of the ORR on polycrystalline $\mathrm{Pt}_{3} \mathrm{Y}$ in Fig. $3 b .{ }^{28}$ For any given surface, the ORR activity can be related to the free energy diagram on the basis of two primary assumptions: (a) all materials have the same maximum activity 
per site at a very high overpotential 9 and (b) any additional barriers scale with the size of the potential determining step $p^{52,62}$ i.e. they exhibit a Brønsted-Evans-Polanyi (BEP) relationship. ${ }^{63}$ The latter assumption was confirmed by more detailed studies of the ORR, which include the effect of reaction barriers. ${ }^{52,62}$

According to the simplified reaction scheme in Fig. 3, there are four elementary stages in the reaction. In the case of $\mathrm{Pt}_{3} \mathrm{Y}$, two elementary steps are uphill in free energy at fuel cell relevant potentials (i.e. $U<0.9 \mathrm{~V}$ ), $\mathrm{HOO}^{*}$ formation and $\mathrm{HO}^{*}$ reduction, denoted by $\Delta G_{1}$ and $\Delta G_{4}$, respectively. The lack of a measurable current above $1 \mathrm{~V}$ in Fig. $3 \mathrm{~b}$ is due to the large magnitudes of $\Delta G_{1}$ and $\Delta G_{4}$ in this potential range. However, by increasing the overpotential, the driving force for each reaction step is increased (i.e. $\Delta G_{1}$ and $\Delta G_{4}$ are decreased), until all the reaction steps are downhill in free energy. This brings about the exponential increase in the current density in the experimental curve shown in Fig. $3 \mathrm{~b}$. According to Fig. 3a, the potential required for all steps to be downhill in free energy on $\mathrm{Pt}_{3} \mathrm{Y}$ is $0.81 \mathrm{~V}$. The last step to become downhill is the "potential determining step", in this case $\Delta G_{4}$.

Ideally, one could hope for a catalyst which exhibited high current densities for the ORR within a few millivolts of the equilibrium potential. This perfect catalyst would be characterised by a flat free energy diagram at the equilibrium potential of $1.23 \mathrm{~V}$, with $\Delta G_{1}=0$ and $\Delta G_{4}=0$. Only an infinitesimal decrease in electrode potential would be required to make all the reaction steps downhill in free energy. On the basis of Fig. 3, this perfect catalyst would bind $\mathrm{HOO}^{*}$ more strongly than $\mathrm{Pt}_{3} \mathrm{Y}$ and $\mathrm{O}^{*}$ and $\mathrm{HO}^{*}$ more weakly. However, it turns out that it is not possible to vary the adsorption energies of these intermediates, i.e. $\Delta G_{\mathrm{O}^{*}}, \Delta G_{\mathrm{HO}^{*}}$ and $\Delta G_{\mathrm{HOO}^{*}}$, independently of each other by changing the catalyst material. A surface that binds $\mathrm{O}^{*}$ strongly can also be expected to bind $\mathrm{HO}^{*}$ or $\mathrm{HOO}^{*}$ strongly, as each adsorbate binds to the surface via the oxygen atom..$^{55,64,65}$ The adsorption energies are in fact linearly dependent, as shown in Fig. 4. The figure also shows that the difference between $\Delta G_{\mathrm{HO}^{*}}$ and $\Delta G_{\mathrm{HOO}^{*}}$ is constant at $\sim 3.2 \mathrm{eV}$. Even in solution, there is a constant difference of $\sim 3.4 \mathrm{eV}$ between the free energy of $\mathrm{HO}^{-}$and $\mathrm{HOO}^{-}$aqueous species. ${ }^{6} \mathrm{This}$ would suggest that this relationship is universal, and independent of the bond that oxygen forms. This difference in free energy between the intermediates is obviously a function of potential.

Although $\Delta G_{\mathrm{OOH}^{*}}-\Delta G_{\mathrm{OH}^{*}} \approx 3.2 \mathrm{eV}$, at $0 \mathrm{~V}$ RHE, it is $\sim 0.8$ $\mathrm{eV}$ at the equilibrium potential of $1.23 \mathrm{~V}$. This sets a minimum value for $\Delta G_{1}+\Delta G_{4}=0.8 \mathrm{eV}$. For the optimal catalyst, the overpotential for the two steps is shared equally, i.e. $\Delta G_{1}=$ $\Delta G_{4} \approx 0.4 \mathrm{eV}$, as shown in Fig. 4. This is approximately the case for the $\mathrm{Pt}_{3} \mathrm{Y}$ shown in Fig. 3. Consequently, the best that one could hope for on a metal surface is that an $\sim 0.4 \mathrm{~V}$ overpotential is needed to make each reaction step downhill in free energy. $\|$

\footnotetext{
I At this high overpotential, where the maximum activity would be obtained, the reaction would be barrierless. This is difficult to probe experimentally, as the current will become diffusion limited well before it reaches this point.

|| This situation contrasts with a two-electron reaction, such as hydrogen evolution or chlorine evolution, which only involves one intermediate. ${ }^{68-70}$ As for the oxygen reduction reaction, the "perfect" catalyst would have a flat free energy diagram at the equilibrium potential. Given that only one intermediate needs to be taken into account, such a catalyst can be found easily. In the case of the hydrogen evolution reaction, it is $\mathrm{Pt}^{51,68}$ and in the case of the chlorine evolution reaction, it is $\mathrm{RuO}_{2}{ }^{69}$
}

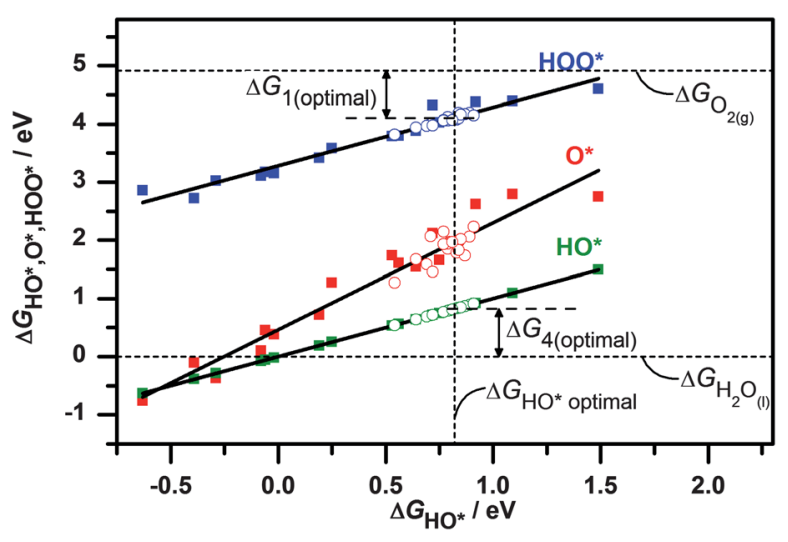

Fig. 4 Theoretical plot of free energies of adsorption of $\mathrm{OOH}^{*}, \mathrm{OH}^{*}$ and $\mathrm{O}^{*}, \Delta G_{\mathrm{OOH}^{*}}, \Delta G_{\mathrm{OH}^{*}}$ and $\Delta G_{\mathrm{O}^{*}}$, respectively, as a function of $\Delta G_{\mathrm{OH}^{*}}$, for (111), (100) and (211) pure metal surfaces (shown with filled squares), ${ }^{64,65}$ as well as Pt overlayers on Pt-alloy surfaces (shown with open circles) ${ }^{67}$

Less active catalysts provide a more unequal distribution between the binding of the different intermediates, i.e. $\Delta G_{1} \ll$ $\Delta G_{4}$ or $\Delta G_{1} \gg \Delta G_{4}$.

As a result of the scaling relations shown in Fig. 4, knowledge of the binding energy of one intermediate provides us with an accurate estimate of the binding energy of the other reaction intermediates. As a consequence of this, we are able to predict the overpotential required to drive the reaction at a high current density, i.e. the ORR activity, as a function of the hydroxyl binding energy, $\Delta G_{\mathrm{HO}^{*}}$. This is shown by the dashed line on the volcano plot in Fig. $5 .{ }^{37,42}$ The data points represent the experimental ORR activity of a number of different catalysts, plotted as a function of the theoretical hydroxyl binding energy, $\Delta G_{\mathrm{HO}}{ }^{25,26,28,71-74}$ These surfaces incorporate the most active man-made metal catalysts ever reported. Apart from bulk alloys, the plot also shows the "Pt-monolayer" surfaces developed by Adzic and co-workers, whereby a monolayer of $\mathrm{Pt}$ is deposited on a single crystal structure of another metal, ${ }^{71,72}$ and the $\mathrm{Cu} / \mathrm{Pt}(111)$ near-surface alloy (described in more detail below). ${ }^{73}$ Since they were collected by different research groups, all values have been normalised with respect to pure Pt. The data roughly follow the theoretical predictions. ${ }^{37,42}$ Due to the scaling relations, we could equally have plotted the volcano as a function of the $\mathrm{O}^{*}$ or $\mathrm{HOO}^{*}$ binding energies. On the left hand side of the volcano, the overpotential is determined by $\Delta G_{4}, \mathrm{HO}^{*}$ reduction, whereas on the right hand side, $\mathrm{HOO}^{*}$ formation, $\Delta G_{4}$ determines the overpotential. According to the volcano plot, $\mathrm{Pt}$ binds HO* $\sim 0.1 \mathrm{eV}$ too strongly for optimal activity. However, the plot demonstrates that the catalysts which show enhancements in activity over $\mathrm{Pt}$, such as $\mathrm{Pt}_{3} \mathrm{Ni}, \mathrm{Pt}_{3} \mathrm{Co}$ and $\mathrm{Pt}_{3} \mathrm{Y}$, have slightly weaker bonds to $\mathrm{HO}^{*}$ than pure $\mathrm{Pt}$.

The notion that the optimal catalyst for a given reaction is that which exhibits intermediate binding to its intermediates was first proposed by Sabatier over 100 years ago. ${ }^{77}$ The volcano plot is a quantitative manifestation of Sabatier's principle and is widely used in both gas-phase heterogeneous catalysis and electrocatalysis. ${ }^{28,55,68,78-87}$

It is important to stress that the dashed line on the volcano plot in Fig. 5 represents an upper limit to the activity that we would expect for a metal surface. Full consideration of the reaction kinetics would likely decrease the maximum enhancement over 


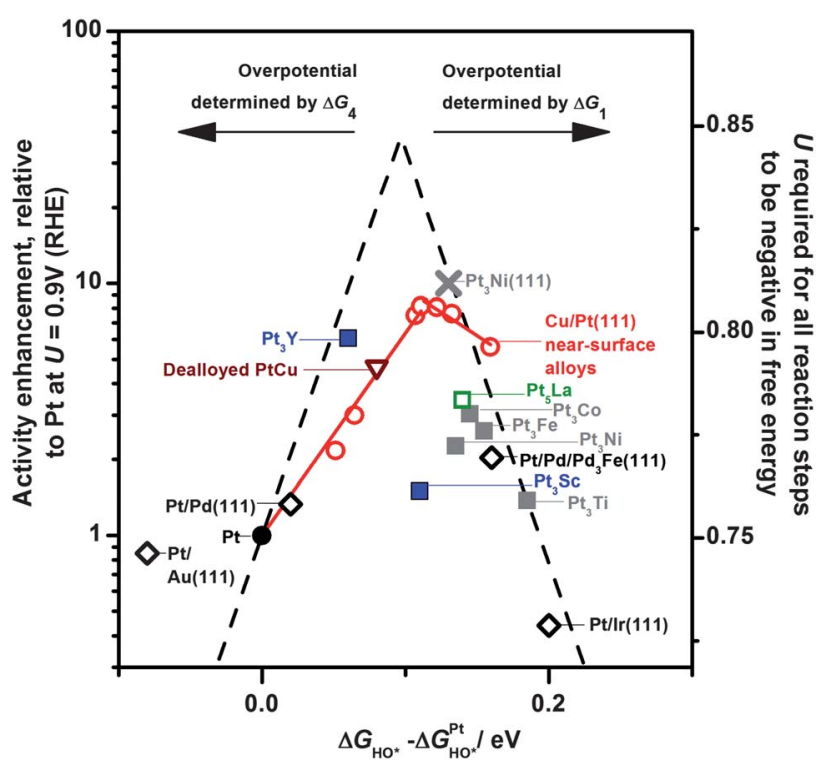

Fig. 5 Volcano plot for different catalysts with Pt-overlayers: experimental ORR activity enhancement as a function of hydroxyl binding energy, $\Delta G_{\mathrm{HO}^{*}}$, both relative to pure Pt. All data are at $U=0.9 \mathrm{~V}$, with respect to a reversible hydrogen electrode (RHE). From: (diamonds) Pt monolayers supported on single-crystal metal electrodes, ${ }^{71,75}$ with $\Delta G_{\mathrm{HO}^{*}}$ from ref. 46 and 72; (grey squares) vacuum-annealed polycrystalline alloys of Pt with late transition metals, ${ }^{26}$ with $\Delta G_{\mathrm{HO}^{*}}$ estimated from $\Delta G_{\mathrm{O}^{*}}$, i.e. $\Delta G_{\mathrm{HO}^{*}}-\Delta G_{\mathrm{HO}^{*}}^{\mathrm{Pt}} \approx 0.5\left(\Delta G_{\mathrm{O}^{*}}-\Delta G_{\mathrm{O}^{*}}^{\mathrm{Pt}}\right) ;{ }^{64,76}$ (crosses) vacuum annealed $\mathrm{Pt}_{3} \mathrm{Ni}(111)$, ${ }^{25}$ also with $\Delta G_{\mathrm{HO}^{*}}$ estimated from $\Delta G_{\mathrm{O}^{*}}$; (blue squares) sputter-cleaned polycrystalline alloys of $\mathrm{Pt}$ and early transition metals, with $\Delta G_{\mathrm{HO}^{*}}$ calculated for $25 \%$ subsurface coverage, in the case of $\mathrm{Pt}_{3} \mathrm{Y}$ with $1 / 4 \mathrm{ML} \mathrm{O}^{*}$ preadsorbed, ${ }^{28}$ (inverted triangles) dealloyed $\mathrm{PtCu}$ nanoparticles, ${ }^{74}$ with $\Delta G_{\mathrm{HO}^{*}}$ for $\mathrm{Pt}(111)$ under $-2.3 \%$ compressive strain; ${ }^{67}$ (red circles) $\mathrm{Cu} / \mathrm{Pt}(111)$ near-surface alloys, joined with a red line to guide the eye, where the $\Delta G_{\mathrm{OH}^{*}}-\Delta G_{\mathrm{OH}^{*}}^{\mathrm{pt}}$ is estimated from the voltammetric shift in the $\mathrm{HO}^{*}$ adsorption peak in the base voltammogram; ${ }^{73}$ (open squares) sputter-cleaned polycrystalline $\mathrm{Pt}_{5} \mathrm{La}$, from the current work. The dashed lines are theoretical predictions, based on a simple Sabatier analysis. ${ }^{55,61}$ All catalyst were tested in $\mathrm{O}_{2}$-saturated $0.1 \mathrm{M}$ $\mathrm{HClO}_{4}$, using a rotating ring disk electrode (RRDE) assembly.

Pt at the peak of the volcano. ${ }^{61}$ Even so, the generally good agreement between experiment and theory confirms the strength of this model in describing trends in ORR activity.

\section{How to reach the peak of the volcano?}

Above, we established that the most active catalyst for the ORR should exhibit slightly weaker binding than Pt to its intermediates, $\mathrm{O}^{*}, \mathrm{HO}^{*}$ and $\mathrm{HOO}^{*}$. In principle, it should be possible to find a number of different metal alloy surfaces that satisfy this requirement. ${ }^{88}$ However, the cathodes of a PEM fuel cell operate under very acidic ( $\mathrm{pH} \approx 0$ ) and oxidising conditions. This renders almost all metals thermodynamically unstable at high potentials. Consequently, the vast majority of research into ORR catalysis has been focussed on Pt and its alloys, as they constitute the only class of materials that are both active and stable.

In ORR catalysts based on Pt-alloys, the surface layer is almost always composed of pure $\mathrm{Pt}^{25,27,73,74,89}$ The less noble solute metal, e.g. $\mathrm{Co}, \mathrm{Ni}, \mathrm{Fe}, \mathrm{Cu}$, or $\mathrm{Y}$, would be unstable at the surface under operating conditions. ${ }^{13}$ The Pt overlayer provides kinetic stability against the dissolution of the solute metal. The overlayer can be formed in two different ways: either by acid leaching, for example upon exposure to the fuel cell electrolyte, or by vacuum annealing in an inert or reducing atmosphere. ${ }^{89}$

The leached structure was denoted by Stamenkovic et al. as a "Pt-skeleton" surface. ${ }^{89}$ The Pt overlayer is typically $1-2 \mathrm{~nm}$ in thickness, with a negligible amount of the solute metal. The structure was first reported by Watanabe and co-workers, but has since been reported by several other groups. ${ }^{27,41,74,89-91}$ Electrochemical scanning tunnelling microscopy (EC-STM) experiments have shown that on a leached PtFe thin film, ordered (111) facets form on the catalyst surface..$^{22}$

The vacuum annealed structure was denoted by Stamenkovic et al. as a "Pt-skin" surface. ${ }^{89}$ The Pt overlayer is typically 1 monolayer thick. The driving force for the formation of the Pt-skin is the lower surface energy of $\mathrm{Pt}$, relative to the solute metal. In the case of $\mathrm{Pt}_{3} \mathrm{Ni}$ or $\mathrm{Pt}_{3} \mathrm{Co}$, upon annealing, the $\mathrm{Ni}$ or $\mathrm{Co}$ in the initially bulk terminated surface will exchange with $\mathrm{Pt}$ in the second layer. This results in an ordered surface with an oscillatory concentration profile, with an enrichment of the solute metal in the second layer. ${ }^{25,93}$ Although this profile was first observed under ultra-high vacuum (UHV) conditions, surface X-ray scattering experiments showed that for $\mathrm{Pt}_{3} \mathrm{Ni}(111)$ the structure was also stable in perchloric acid solution under an applied potential. ${ }^{25}$ The outcome of Markovic and co-workers' extensive study of $\mathrm{Pt}_{3} \mathrm{Ni}(111)$ was a surface that exhibited record breaking ORR activity, as shown in the volcano plot in Fig. $5 .{ }^{25}$ For both Pt-skin and Pt-skeleton surfaces, the effect of alloying is to modify the electronic structure of the Pt overlayer to weaken the binding of the surface to the ORR intermediates. ${ }^{26,94}$ This can be brought about by two effects, ligand effects and strain effects. ${ }^{95-98}$

Ligand effects are brought about by subsurface alloying, i.e. when the electronic structure of the Pt surface atoms is modified by solute metal atoms of a different composition in the second atomic layer. ${ }^{95}$ This also weakens the binding of the surface to the oxygen-containing intermediates of the ORR. Strain effects occur when the $\mathrm{Pt}$ overlayer is compressed laterally. ${ }^{74,96}$ This brings about a downshift in the d-band centre, resulting in a surface which binds adsorbates such as $\mathrm{O}^{*}, \mathrm{HO}^{*}$ and $\mathrm{HOO}^{*}$ weaker than unstrained $\mathrm{Pt}$. This can be achieved by placing the $\mathrm{Pt}$ overlayer on a core with a smaller lattice parameter than Pt.

In most Pt-alloy or Pt overlayer catalysts for the ORR, it is difficult to deconvolute the interplay between strain and ligand effects in weakening the binding to $\mathrm{O}^{*}$ or $\mathrm{OH}^{*}{ }^{26,71,72,89}$ For instance, $\mathrm{Pt}_{3} \mathrm{Ni}$ and $\mathrm{Pt}_{3} \mathrm{Co}$ have a smaller lattice parameter than pure $\mathrm{Pt}$, suggesting that their higher activity can be rationalised on the basis of strain effects. ${ }^{99,100}$ Nonetheless, the most active forms of polycrystalline $\mathrm{Pt}_{3} \mathrm{Ni}$ and $\mathrm{Pt}_{3} \mathrm{Co}$ structures are the vacuum annealed, Pt-skin structures, with an enrichment of the solute atom in the second atomic layer, suggesting that ligand effects are also important. ${ }^{26,89}$

The effects of subsurface alloying and lattice strain on the ORR were recently orthogonalised by two independent investigations, both making use of the $\mathrm{Pt}-\mathrm{Cu}$ system. ${ }^{73,74}$ In our own study, we probed the effect of subsurface alloying upon the ORR activity of a $\operatorname{Pt}(111)$ single crystal, in the absence of bulk lattice strain. We achieved this using a $\mathrm{Cu} / \mathrm{Pt}(111)$ near-surface alloy, shown in the illustration and non-destructive depth profiles, produced using angle resolved X-ray photoelectron spectroscopy 

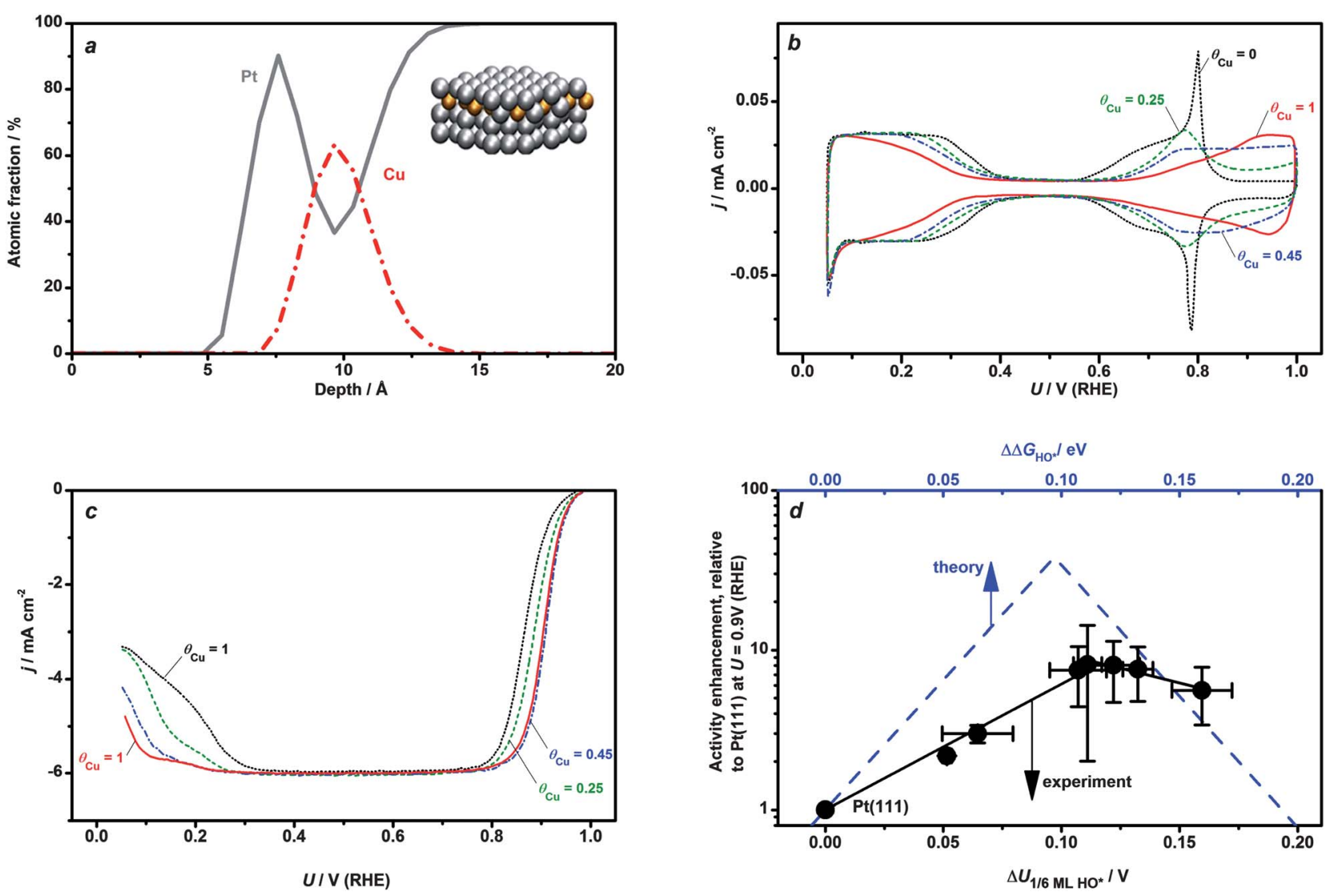

Fig. 6 Investigation of subsurface alloying on activity of $\mathrm{Pt}(111)$ for oxygen reduction, using $\mathrm{Cu} / \mathrm{Pt}(111)$ near-surface alloy (NSA) ${ }^{73}$ (a) Nondestructive depth profile of NSA, determined using angle resolved XPS, with a schematic illustration of the structure in the inset, (b) cyclic voltammograms of $\mathrm{Cu} / \mathrm{Pt}(111) \mathrm{NSAs}$ in $\mathrm{N}_{2}$-saturated $0.1 \mathrm{M} \mathrm{HClO}_{4}$, at $23{ }^{\circ} \mathrm{C}$, for different values of $\theta_{\mathrm{Cu}}$, the amount of Cu initially electrodeposited prior to formation of the near-surface alloy, (c) voltammograms of $\mathrm{Cu} / \mathrm{Pt}(111) \mathrm{NSAs}_{\text {in }} \mathrm{O}_{2}$-saturated $0.1 \mathrm{M} \mathrm{HClO}_{4}$, at $60{ }^{\circ} \mathrm{C}, 1600 \mathrm{RPM}$, for different values of $\theta_{\mathrm{Cu}}$ and (d) volcano plot, with the black data points denoting the experimental activity enhancement, relative to $\operatorname{Pt}(111)$ at $U=0.9 \mathrm{~V}$, as a function of $\Delta U_{1 / 6} \mathrm{ML} \mathrm{HO}^{*}$, where $\Delta U_{1 / 6} \mathrm{ML} \mathrm{HO}^{*}$ is the voltammetric shift in potential required to form $1 / 6 \mathrm{ML} \mathrm{HO}$, relative to Pt(111), from the data shown in (b). The continuous black line is to guide the eye; the dashed blue line shows the earlier theoretical predictions of the activity enhancement, relative to $\operatorname{Pt}(111)$, as a function of $\Delta \Delta G_{\mathrm{HO}^{*}}$, the shift in $\Delta G_{\mathrm{HO}^{*}}$, relative to $\mathrm{Pt}(111)$, based on a Sabatier analysis. ${ }^{55,61}$ Copyright 2011 American Chemical Society. Adapted with permission from Stephens et al. ${ }^{73}$

(XPS), in Fig. 6a. ${ }^{73}$ This structure is formed by "underpotentially" depositing up to a monolayer of $\mathrm{Cu}$ onto the surface of $\mathrm{Pt}(111)$, and subsequently annealing the crystal. The $\mathrm{Cu}$ is stabilised in the second layer. ${ }^{101}$ We found that subsurface copper brought about a positive shift in the position of the voltammetric peak for $\mathrm{HO}^{*}$ electrosorption between $0.6 \mathrm{~V}$ and $1 \mathrm{~V}$, as shown in Fig. 6b. This correlated with a significant increase in ORR activity, as shown in Fig. 6c, with a peak 8-fold enhancement over pure $\mathrm{Pt}$ at $\sim 50 \%$ subsurface $\mathrm{Cu}$ concentration. The experimental shift in the $\mathrm{HO}^{*}$ adsorption peak in Fig. $6 \mathrm{~b}$ as a function of subsurface $\mathrm{Cu}$ coverage was in excellent agreement with the DFT calculated value of the $\Delta G_{\mathrm{HO}^{*}}$. Since the bulk of the crystal was composed of $\mathrm{Pt}$, there was no bulk lattice strain. This suggests that the destabilisation of $\mathrm{HO}^{*}$ was largely due to the ligand effect. By plotting the activity enhancement as a function of the shift in the position of the $\mathrm{HO}^{*}$ adsorption peak, we demonstrated that this maximum occurred on the surface which bound $\mathrm{HO}^{*} \sim 0.1 \mathrm{eV}$ weaker than $\mathrm{Pt}(111)$, as shown in Fig. 6d. To the best of our knowledge, our work provided the strongest validation to date of the volcano model. Strain, or the Pt-Pt interatomic distance, has long been recognised as a key determinant of ORR activity in Pt-alloys. ${ }^{30,31}$
Nonetheless, most early studies took a more phenomenological approach, and made no attempts to separate strain effects from ligand effects. Arguably, the most comprehensive study of strain effects for the ORR is that of Strasser et al. upon dealloyed $\mathrm{PtCu}_{x}$. These catalysts exhibited up to a 6-fold improvement in activity over pure Pt nanoparticles. ${ }^{74}$ Ex situ characterisation suggested that the nanoparticles were encased with a $\sim 1 \mathrm{~nm}$ thick overlayer of strained pure $\mathrm{Pt}$ over a $\mathrm{Cu}$-rich core (completely distinct from the $\mathrm{Cu} / \mathrm{Pt}(111)$ near-surface alloy shown in Fig. 6). Fig. 7 demonstrates that the ORR activity of dealloyed $\mathrm{PtCu}_{x}$ is correlated to the strain in the Pt shell. According to their DFT calculations, there should have been a maximum in the activity at a compressive strain of around $-2 \%$, which would correspond to the peak in the volcano in Fig. 5. They attributed the absence of such a peak in their experimental data to strain relaxation at the surface of the Pt overlayer. Finally, they used a series of spectroscopic experiments on Pt overlayers on $\mathrm{Cu}(111)$ to understand the effect of compressive strain on the electronic structure of the $\mathrm{Pt}$ overlayer. These measurements showed that the d-band centre shifted downwards, resulting in an increased occupancy of the $\mathrm{O}$ $2 \mathrm{p}$ and $\mathrm{Pt} 5 \mathrm{~d}$ anti-bonding states. This result, consistent with the 


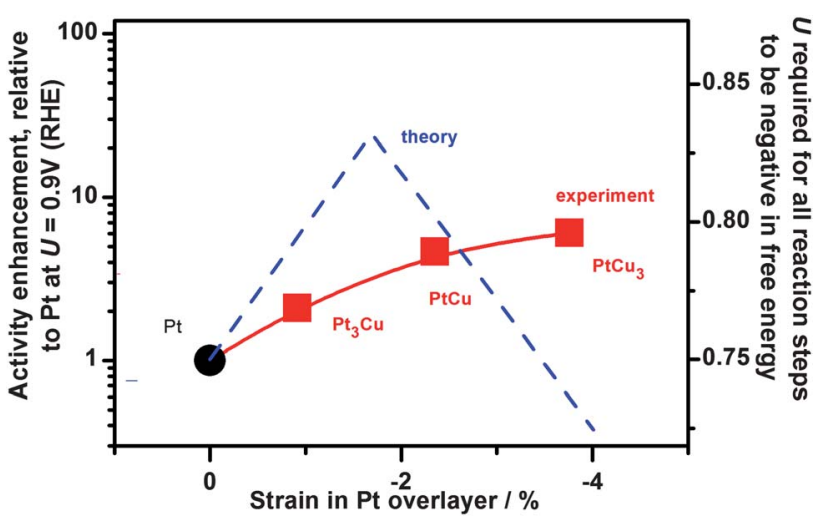

Fig. 7 Experimental ORR activity as a function of compressive strain in $\mathrm{Pt}$ overlayer for dealloyed $\mathrm{PtCu}_{x}$ nanoparticles, adapted from Strasser et al. $^{74}$ The data are taken from the particles that were preannealed at $800^{\circ} \mathrm{C}$. The experimental data points are joined by a red line to guide the eye. Each point is labelled with the composition of the catalyst precursors, prior to dealloying. The dashed blue line represents a theoretical volcano where the active site is modelled as strained $\mathrm{Pt}(111)$. Note that the volcano is modified slightly, relative to the version plotted by Strasser et al. $;^{74}$ they plotted an asymmetric version which assumed a dissociative reaction mechanism; ${ }^{55}$ the symmetric version plotted here reflects the outcome of more recent DFT calculations, which suggest that an associative mechanism is more likely. ${ }^{52,60}$ Copyright 2010, data reproduced with permission from Macmillan Publishers Ltd.

d-band model, ${ }^{96}$ confirms why the Pt overlayer on dealloyed $\mathrm{PtCu}_{x}$ nanoparticles would bind $\mathrm{O}^{*}$ or $\mathrm{HO}^{*}$ more weakly than on pure Pt nanoparticles.

In summary, the $\mathrm{Pt}-\mathrm{Cu}$ system has been particularly useful in elucidating how alloying can be used to tune the reactivity of $\mathrm{Pt}$ towards the peak of the ORR volcano.

\section{Translating the knowledge from extended surfaces to nanoparticles}

Most of the experimental investigations described above were performed on extended surfaces of Pt alloys, tested in perchloric acid solutions, using a RDE or RRDE assembly. The elucidation of surface composition and structure is more facile upon extended surfaces, especially on single crystals. Moreover, their well-defined surface area removes ambiguities in comparing ORR activities.**

** A word of caution is needed regarding the estimation of the electrochemically active surface areas of $\mathrm{Pt}$ alloys. This is typically determined in the same way as for $\mathrm{Pt}$, either by integrating the charge required for $\mathrm{H}^{*}$ adsorption between $0.5 \mathrm{~V}$ and $0.05 \mathrm{~V}$, or by measuring the charge required to electro-oxidise a monolayer of $\mathrm{CO}^{*}{ }^{102}$ The implicit assumption is that the coverages of $\mathrm{H}^{*}$ or $\mathrm{CO}^{*}$ upon $\mathrm{Pt}$ alloys are independent of surface structure and alloying. However, studies on extended surfaces, in particular single crystals, have demonstrated that the coverages of $\mathrm{H}^{*}$ or $\mathrm{CO}^{*}$ upon $\mathrm{Pt}$ alloys are significantly decreased in comparison to pure $\mathrm{Pt}$, due to weaker interaction with these adsorbates. ${ }^{25,73,101,103,104}$ Consequently, not only could one anticipate that a Pt-alloy surface would bind the intermediates of the ORR more weakly, resulting in higher activity, but it would also appear to have a lower surface area. The outcome of this is that the apparent activity enhancement afforded by Pt alloys over Pt could be exaggerated on nanoparticles, due to the inherent ambiguity in the measurement of the surface area. Despite this, the ease at which the apparent electrochemically active surface area can be measured in situ still makes it a valuable diagnostic tool.
Nonetheless, the poor dispersion afforded by extended surfaces means that they would never be used in a real fuel cell. Most typically, the Pt-alloys used as ORR catalysts in a PEMFC cathode would be in nanoparticulate form, on a high surface area carbon support, ${ }^{9}$ although nanostructured thin films are also a possibility. ${ }^{105,106}$

In most of the published literature, the performance of carbonsupported nanoparticulate catalysts for the ORR is evaluated in a RDE assembly in $\mathrm{HClO}_{4}$, using the "thin-film" method., ${ }^{702,107,108}$ Catalysts can be tested much more easily and more reproducibly using this method than in a PEMFC. Moreover, it yields ORR activities which are remarkably close to those measured in a PEMFC. ${ }^{7}$

\section{Pt cathode catalysts}

Activity. There are two primary means by which the mass activity of Pt can be increased: (a) improving its intrinsic activity and (b) increasing the number of active sites. Until recently, most catalyst development was focussed on the latter approach, by improving the $\mathrm{Pt}$ dispersion. This strategy yielded clear dividends: raising the dispersion from $\sim 5$ to $\sim 80 \mathrm{~m}^{2} \mathrm{~g}_{\mathrm{Pt}}{ }^{-1}$, equivalent to a decrease in mean particle diameter from $\sim 15 \mathrm{~nm}$ to $\sim 3 \mathrm{~nm}$, respectively, results in a 5-fold improvement in Pt mass activity, in $\mathrm{A}_{\mathrm{Pt}^{-1}}{ }^{-1}$. However, it turns out that the mass activity cannot be improved much further by improving the dispersion beyond $80 \mathrm{~m}^{2} \mathrm{~g}_{\mathrm{Pt}}{ }^{-1}$, as there is a peak in mass activity. This is because of a pronounced decrease in specific activity as a function of the $\mathrm{Pt}$ dispersion, i.e. small particles are less active for the ORR than extended surfaces. This particle size effect has been reported by a number of different research groups, ${ }^{7,102,110-113}$ although there is some controversy regarding the size range over which the effect is most pronounced. ${ }^{111}$ Recent DFT calculations provide an explanation for this phenomenon. ${ }^{65,109} \mathrm{~A}$ decrease in particle size brings about an increased population of under-coordinated facets of Pt, relative to the terraces, (111) and (100). As discussed earlier, on $\mathrm{Pt}(111)$, the overpotential for the ORR is due to the significant barrier for $\mathrm{HO}^{*}$ removal, ${ }^{52,61}$ hence its position on the strong-binding side of the volcano plot in Fig. 5.

More open facets, such as steps, edges and kinks, will tend to bind adsorbates such as $\mathrm{HO}^{*}$ more strongly. Consequently, on such facets there will be even greater barriers (or overpotential) for HO* removal; as a consequence, the contribution to the ORR activity from these under-coordinated sites would be negligible. Thus a decrease in particle size should result in a decrease in specific activity, as shown in Fig. 8b. According to this theoretical model, the surface specific activity of particles greater than $\sim 10 \mathrm{~nm}$ in diameter should approximate that of an extended $\mathrm{Pt}$ (111) surface. Moreover, the model predicts a peak in mass activity at around $\sim 3 \mathrm{~nm}$, Fig. $8 \mathrm{c}$, consistent with the experiments of Gasteiger et al. (ref. 7).††

$\dagger$ In the literature there is some controversy regarding the range over which the particle size effect is most pronounced. ${ }^{111}$ This is partially due to the experimental challenges in measuring the ORR activity of industrial Pt catalysts, which are on high surface area supports. To this end, we are currently carrying out model experiments of the ORR activity of size-selected $\mathrm{Pt}$ nanoparticles ${ }^{114}$ on planar substrates. This will allow us to verify with certainty the theoretical predictions described in Fig. 8. 

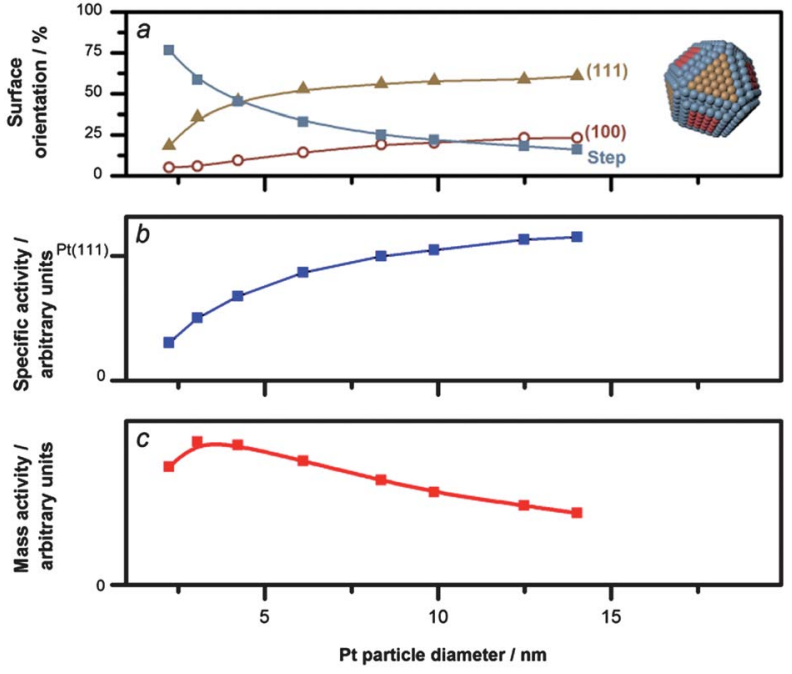

Fig. 8 (a) Proportion of surface facets on Pt nanoparticles as a function of particle size, based on a modified Wulff construction, as depicted in the inset, (b) theoretical trends in surface specific ORR activity, as a function of particle size, relative to the activity of $\mathrm{Pt}(111)$, by taking into account the theoretical activity and relative proportions of the facets depicted in (a), and (c) theoretical trends in ORR activity, where the current is normalised according to the mass of Pt. All data were adapted, with permission, from Tritsaris et al. ${ }^{109}$ Copyright 2011, Springer.

Given the experimental and theoretical evidence that undercoordinated sites should be inactive for the ORR on $\mathrm{Pt},{ }^{7,102,110-113}$ it is somewhat counter-intuitive that some stepped single crystals show an enhanced activity for the ORR in comparison to $\operatorname{Pt}(111) .{ }^{115,116}$ The most active of these stepped surfaces, the $\mathrm{Pt}(331)$ surface, shows a $\sim 4$-fold improvement in ORR activity over $\mathrm{Pt}(111)$ at $0.9 \mathrm{~V} \cdot{ }^{116}$ According to our theoretical understanding of the ORR, this improvement in activity should be related to the weaker binding of the surface to HO*. This notion is supported by the voltammograms in $\mathrm{N}_{2}$-saturated $0.1 \mathrm{M}$ $\mathrm{HClO}_{4}$ for $\mathrm{Pt}(111)$ and $\mathrm{Pt}(331) .{ }^{117} \mathrm{On} \mathrm{Pt}(331)$, there is a positive shift, relative to $\operatorname{Pt}(111)$, in the peak that is usually assigned to $\mathrm{HO}^{*}$ adsorption; this confirms that there is an $\mathrm{HO}^{*}$ or $\mathrm{O}^{*}$ species on $\operatorname{Pt}(331)$ that binds the surface slightly weaker than $\operatorname{Pt}(111)$ (we discussed this type of voltammetric analysis in the section "How to reach the peak of the volcano?"). Presumably, this HO* species is on the terrace sites of (331); step sites bind $\mathrm{HO}^{*} \sim 0.8$ eV stronger than $\mathrm{Pt}(111),{ }^{55,65,109}$ which would suggest that $\mathrm{HO}^{*}$ would adsorb onto the steps of $\operatorname{Pt}(331)$ at very low potentials, around its potential of zero total charge, $0.2 \mathrm{~V} .{ }^{118}$ A recent study suggested that strongly bound $\mathrm{HO}^{*}$ at the step should have a negligible effect to the binding of $\mathrm{HO}^{*}$ on the adjacent terraces. ${ }^{109}$ Consequently, we speculate that the weakened binding of the terrace sites of $\operatorname{Pt}(331)$ could be related to the reconstruction of $\mathrm{Pt}(331)$ in perchloric acid. ${ }^{119}$ Otherwise the structure of the water layer might be perturbed by the steps, which could decrease the extent to which $\mathrm{HO}^{*}$ is stabilised by coadsorbed $\mathrm{H}_{2} \mathrm{O}$ * relative to $\mathrm{Pt}(111) .{ }^{120}$ Clearly, further investigations are needed to explain this phenomenon. Nonetheless, in contrast to experiments on single crystals, we find no evidence to suggest that steps or other undercoordinated sites can increase the ORR activity of Pt nanoparticles. ${ }^{65,109,114}$
Stability. Stabilising Pt nanoparticles in the cathode of a fuel cell seems to be even more challenging than controlling their activity. Cathode catalyst degradation limits the useful lifetime of a PEMFC. ${ }^{11,12,121,122}$ This is due to (a) the corrosion of the carbon support at high potentials, leading to Pt nanoparticle detachment or loss of electrical contact (a topic which is beyond the scope of the current article) $)^{123,124}$ and (b) the dissolution of Pt itself. Both effects manifest themselves as an effective loss of the Pt surface area with time. This is monitored in situ by integrating the charge required to adsorb $\mathrm{H}^{*}$ or electro-oxidise $\mathrm{CO}^{*}$ on the surface (see the earlier footnote**), or else ex situ by scanning electron microscopy (SEM) or transmission electron microscopy (TEM). Following its dissolution, Pt tends to redeposit elsewhere, either on larger nanoparticles in the diffusion layer via the Ostwald ripening mechanism or in the ionomer phase in the membrane. ${ }^{121}$

Pt dissolution seems to be more pronounced on small nanoparticles, particularly below $4 \mathrm{~nm} \cdot{ }^{11,112,125-129}$ Moreover, it is enhanced at high potentials, ${ }^{\mathbf{1 2 1 , 1 3 0}}$ especially during potential cycling, for example during the start up and shut down of a fuel cell. ${ }^{121,128,129,131}$

There is no widespread consensus in the literature regarding whether the dissolution of Pt occurs directly from the metallic phase: ${ }^{12,130,132}$

$$
\mathrm{Pt} \rightarrow \mathrm{Pt}^{2+}+2 \mathrm{e}^{-}
$$

via the formation of oxidised $\mathrm{Pt}$ (in the form of a $2 \mathrm{D}$ adsorbate phase or a 3D subsurface oxide) and its subsequent chemical dissolution:

$$
\begin{gathered}
\mathrm{Pt}+x \mathrm{H}_{2} \mathrm{O} \rightarrow \mathrm{PtO}_{x}+2 x \mathrm{H}^{+}+2 x \mathrm{e}^{-} \\
\mathrm{PtO}_{x}+2 x \mathrm{H}^{+} \rightarrow \mathrm{Pt}^{2 x+}+x \mathrm{H}_{2} \mathrm{O}
\end{gathered}
$$

or even the reduction of the oxide: ${ }^{133,134}$

$$
\mathrm{PtO}_{2}+4 \mathrm{H}^{+}+2 \mathrm{e}^{-} \rightarrow \mathrm{Pt}^{2+}+2 \mathrm{H}_{2} \mathrm{O}
$$

It is worth noting that the dissolution of bulk, metallic $\mathrm{Pt}$ is thermodynamically favoured above $\sim 1 \mathrm{~V} .{ }^{13}$ However, the average cohesive energy of a Pt atom in a nanoparticle is lower than in the bulk, due to the contribution of the surface energy, meaning that its chemical potential is higher. ${ }^{125-127,132,135}$ Consequently, the dissolution potential of a nanoparticle will decrease with a decrease in size, in accordance with the following equation: ${ }^{136}$

$$
U_{\mathrm{diss}}^{\text {particle }}=U_{\mathrm{diss}}^{\text {bulk }}-\Delta \mu_{\mathrm{Pt}}^{\text {particle }} / 2 e
$$

where $U_{\text {diss }}^{\text {particle }}$ is the dissolution potential for the entire nanoparticle, $U_{\text {diss }}^{\text {bulk }}$ is the dissolution potential for bulk Pt and $\Delta \mu \mathrm{Pt}$ particle is the change in cohesive energy per Pt atom, relative to bulk Pt, defined as follows: ${ }^{136}$

$$
\Delta \mu_{\mathrm{Pt}}^{\text {particle }}=3 \sigma_{\mathrm{Pt}} V_{\mathrm{Pt}} / r S_{\mathrm{Pt}}
$$

where $\sigma_{\mathrm{Pt}}$ is the surface energy of the particle, $V_{\mathrm{Pt}}$ is the volume of a single $\mathrm{Pt}$ atom, $S_{\mathrm{Pt}}$ is the surface area of a single Pt atom and $r$ is the particle radius. There are several variations of (6) and (7) in the literature, ${ }^{125-127,132,135}$ with the commonality between them 
that $\left(U_{\text {diss }}^{\text {bulk }}-U_{\text {diss }}^{\text {particle }} \propto 1 / r\right.$. The differences depend on how the dissolution is modelled: i.e. via (2), (4) or (5), and whether the surface energy of the dissolving phase is considered to be isotropic or site dependent. Since the surface energy is largely a function of coordination, undercoordinated $\mathrm{Pt}$ atoms are more prone towards dissolution. ${ }^{93,94}$ Models taking into account this site dependency predict an even greater propensity of small nanoparticles towards dissolution than those assuming an isotropic surface energy. ${ }^{136}$

The fact that $\mathrm{Pt}$ dissolution is enhanced under potential cycling calls for more potentiodynamic studies of corrosion phenomena, at a microscopic level. EC-STM studies on Pt(111) in acidic solution have been particularly illuminating in this regard. ${ }^{137-140}$ Itaya and co-workers showed that after a few cycles between $0.05 \mathrm{~V}$ and $1.5 \mathrm{~V}$, an initially ordered Pt terrace becomes corrugated, covered with monoatomic or diatomic pits and islands. ${ }^{137,138}$ According to Wakisaka et al., the first step in this roughening process occurs at anodic potentials, at high coverages of $\mathrm{O}^{*}$, where the $\operatorname{Pt}(111)$ surface starts to mildly buckle, and subsurface oxides form. ${ }^{139}$ Even so, the surface remains largely intact until the reduction sweep, where at $0.5 \mathrm{~V}$, the terraces becomes abruptly more corrugated. This suggests that the reduction of adsorbed $\mathrm{O}^{*}$ or subsurface oxides destabilises the Pt atoms, causing them to be mobile and easily dissolved. Upon repeated cycling between 0.1 and $1.3 \mathrm{~V}$, the corrugation continues, and step edges roughen and grow. Such roughening is likely to have an autocatalytic effect upon the corrosion of Pt, due to the increased susceptibility of undercoordinated sites towards dissolution. ${ }^{141}$

The STM experiments described above were conducted upon single crystals in liquid electrolytes. Nonetheless, we anticipate that the enhanced dissolution of Pt nanoparticles in a fuel cell upon cycling could also be related to surface deformation at high $\mathrm{O}^{*}$ coverages and subsurface oxide formation. Evidence for subsurface oxide formation on Pt was first provided by Conway and co-workers on the basis of purely electrochemical measurements. ${ }^{142}$ X-Ray absorption spectroscopy (XAS) has provided more direct evidence of this phenomenon on $\mathrm{Pt}$ nanoparticles. ${ }^{35,143-146}$ Friebel et al. recently reinterpreted these earlier XAS experiments to suggest that subsurface oxides could form on Pt nanoparticles as early as $0.8 \mathrm{~V} \cdot{ }^{147}$ In summary, surface roughening and subsurface oxide formation are likely to be detrimental to catalyst stability, and thus strategies are required to mitigate these processes.

On the basis of the poor stability and lower activity of small $\mathrm{Pt}$ nanoparticles, it should come as no surprise that some commercial catalyst manufacturers have resorted towards lower degrees of dispersion. For instance, the manufacturer, 3M, has developed nanostructured thin film catalysts, constituting a Pt thin film deposited on nanostructured non-conducting whiskers, as shown in Fig. 9. ${ }^{105}$ These catalysts have a mass activity similar to conventional commercial nanoparticulate catalysts, but exhibit much higher stability and negligible corrosion of the support. Even so, water management is more challenging on these thin films than on conventional nanoparticulate $\mathrm{Pt} / \mathrm{C}$ catalysts. ${ }^{148}$

\section{Nanoparticulate Pt-alloy catalysts}

Carbon supported Pt-alloy catalysts are often pre-annealed at high temperatures in a reducing or inert atmosphere, before

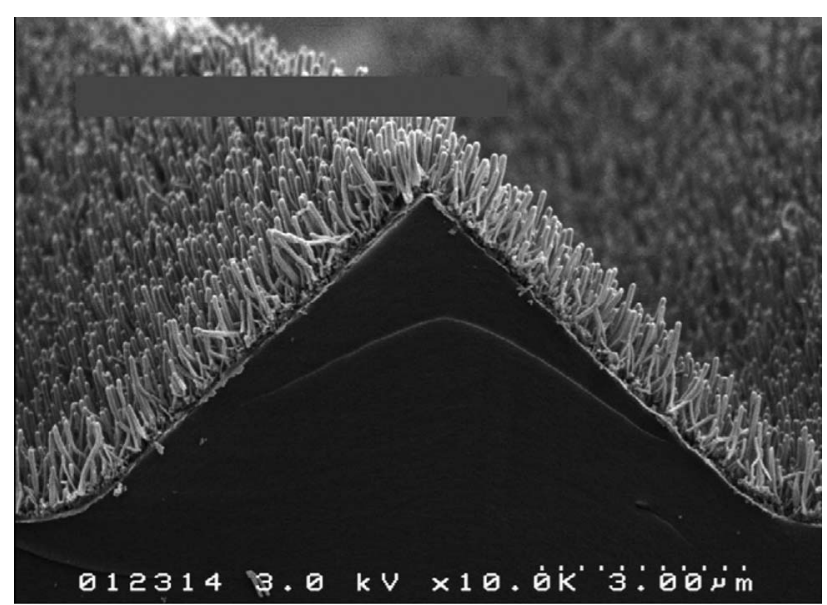

Fig. 9 Scanning electron microscopy images of nanostructured thin film Pt PEMFC catalysts on a nonconducting support, shown in crosssection. Reproduced with permission from Elsevier, copyright 2006. ${ }^{105}$

being employed in a PEMFC. ${ }^{128,149}$ This homogenises their composition. It can also bring about sintering and lower degrees of dispersion. The Pt overlayer is formed by acid leaching. Consequently, the surface resembles the Pt-skeleton structure that we described earlier. ${ }^{150,151}$ The leaching can take place in situ, although this can result in the metal cations poisoning the proton channels in the membrane electrolyte. To avoid this undesired effect, the catalyst can be pre-leached in a liquid electrolyte. ${ }^{7}$

Typically, in a PEMFC, carbon supported nanoparticulate Pt-alloys such as $\mathrm{Pt}_{x} \mathrm{Co} / \mathrm{C}$ provide a 2-fold gain in mass activity and a 4-fold gain in surface specific activity over pure Pt catalysts. ${ }^{7,152}$ The lack of a $1: 1$ correlation between the enhancement in mass activity and surface specific activity could be due to the poorer dispersion of Pt alloy catalysts and artefacts in measuring the electrochemically active surface area (see earlier footnote**). Even higher activities are possible, as demonstrated by dealloyed $\mathrm{PtCu}_{x} / \mathrm{C}$ nanoparticles (described earlier), which exhibit a fourfold enhancement in mass activity over Pt in a PEMFC. ${ }^{153}$

It turns out that catalyst stability is also of critical importance for Pt-alloy catalysts, as is the case for pure Pt. Fig. 10 compares the performance of $\mathrm{Pt} / \mathrm{C}$ and dealloyed $\mathrm{PtCu}_{3} / \mathrm{C}$ after 30000 cycles in a PEMFC between 0.5 and $1 \mathrm{~V}$, from data by Straser and co-workers. ${ }^{149}$ Notably, the Pt-alloy catalysts were preannealed at different temperatures. The catalyst with the highest initial mass activity, $\mathrm{PtCu}_{3} / \mathrm{C}$, annealed at $800^{\circ} \mathrm{C}$, loses over half its mass activity by the end of the experiment. The figure also shows that this is due to a $\sim 55 \%$ loss of surface area and a $\sim 30 \%$ decrease in specific activity. On the other hand, the two Pt/C catalysts only lose $\sim 13 \%$ of their initial mass activity: the $\sim 75 \%$ loss of surface area is offset by a 2.7 to 3.8 fold increase in specific activity (presumably due to an increase in the average particle size). The most stable catalyst was $\mathrm{PtCu}_{3} / \mathrm{C}$, annealed at $950{ }^{\circ} \mathrm{C}$, which exhibited a stable mass activity. The loss of $\sim 25 \%$ of its initial surface area was offset by a $\sim 30 \%$ increase in specific activity.

Other investigators have made observations very similar to those of Strasser and co-workers regarding the performance of Pt-alloys/C in comparison to $\mathrm{Pt} / \mathrm{C}$ over long time scales or under potential cycling in a PEMFC, ${ }^{77,152,154-157}$ namely that: (a) similar 

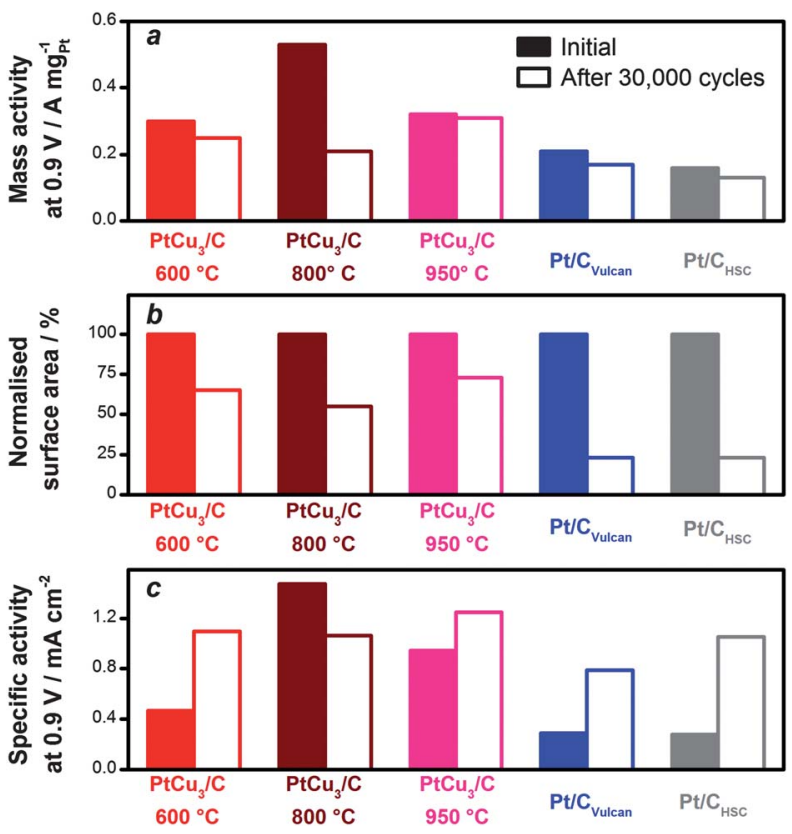

Fig. 10 Stability of dealloyed $\mathrm{PtCu}_{3} / \mathrm{C}$ and $\mathrm{Pt} / \mathrm{C}$ catalysts in a PEMFC, before and after 30000 voltage cycles from 0.5 to $1.0 \mathrm{~V}$ at $100 \mathrm{mV} \mathrm{s}^{-1}$ and $80^{\circ} \mathrm{C}$, adapted from data reported in Neyerlin et al. ${ }^{149}$ (a) Mass activity, (b) surface area normalised to the initial surface area of each catalyst and (c) specific activity. For (b) and (c), the surface area was determined by the voltammetric adsorption of hydrogen between $0.5 \mathrm{~V}$ and $0.05 \mathrm{~V}$ (see footnote**). The dealloyed catalysts were based on an initial $\mathrm{PtCu}_{3}$ precursor, which were annealed prior to dealloying at the temperatures indicated in the figure. $\mathrm{Pt} / \mathrm{C}_{\mathrm{Vulcan}}$ and $\mathrm{Pt} / \mathrm{C}_{\mathrm{HSC}}$ denote two types of commercial Pt catalysts supported on carbon, which were not annealed.

to Pt, the mass activity of Pt-alloys decreases slightly (b) whereas the specific activity of $\mathrm{Pt}$ is stable or tends to increase the specific activity of Pt-alloys changes little or sometimes decreases and (c) there is a slight decrease in the electrochemically active surface area upon the alloys, in contrast to the pronounced decrease exhibited by Pt.

The improved retainment of the surface area of Pt-alloys/C over Pt/C in a PEMFC may suggest that the presence of the less noble solute metal actually stabilises the catalyst. However, it is important to note that this phenomenon could be partially attributed to the ambiguities in measuring the catalyst surface area, as described in the earlier footnote**. With time, the solute component tends to leach out (see below). As the particles dealloy, the affinity of the $\mathrm{Pt}$ overlayer towards $\mathrm{H}^{*}$ or $\mathrm{CO}^{*}$ should increase. Consequently, a slight loss of real surface area, due to Pt dissolution, could be masked by an increased coverage of $\mathrm{H}^{*}$ or $\mathrm{CO}^{*}$ on the Pt-alloy nanoparticles depleted of the solute component.

Neglecting such artefacts from the measurements, there are several explanations available in the literature for the improved ability of Pt alloys to maintain their surface area, relative to pure Pt. Greeley and Nørskov calculated that the dissolution potential of the $\mathrm{Pt}$ overlayer upon $\mathrm{Pt}_{3} \mathrm{Co}(111), \mathrm{Pt}_{3} \mathrm{Ni}(111)$ and $\mathrm{Pt}_{3} \mathrm{Fe}(111)$ would be increased by up to $0.16 \mathrm{~V}$, relative to $\mathrm{Pt}(111) .{ }^{158}$ This stabilisation is related to the increased surface energy of a bulkterminated alloy surface, relative to the Pt-terminated surface. Such considerations would only be valid for a surface with a significant subsurface $\mathrm{Co}, \mathrm{Ni}$ or $\mathrm{Fe}$ content, such as the "Ptskin" catalysts, ${ }^{25,89}$ but not for a catalyst with a thick Pt overlayer, such as dealloyed $\mathrm{PtCu}_{x}{ }^{74}$ Lucas, Markovic and coworkers have proposed that the $\mathrm{Pt}$ overlayer on $\mathrm{Pt}_{3} \mathrm{Ni}(111)$ may be less susceptible to subsurface oxide formation than on $\mathrm{Pt}(111)$, as result of the decreased coverage of $\mathrm{O}^{*}$ and $\mathrm{HO}^{*}$ on its surfaces. ${ }^{99}$ They implicitly assume that the interaction between $\mathrm{Ni}$ and adsorbed $\mathrm{O}$ is insufficient to cause subsurface oxide formation or Ni segregation to the surface. ${ }^{159,160}$

Perhaps the most likely cause of the increased stability of Ptalloys is the high temperatures used to anneal them. ${ }^{128,149}$ Under these conditions, the particles would sinter, their average size would increase and the facets would become more ordered. All these effects would stabilise the catalysts. Indeed, this hypothesis is borne out by the data shown in Fig. 11, adapted from Makharia et al. ${ }^{128}$ where the progression of the normalised surface area upon cycling is plotted for several different types of $\mathrm{Pt} / \mathrm{C}$ catalysts, in comparison to a $\mathrm{PtCo} / \mathrm{C}$ catalyst. The ability of the catalyst to retain its surface area increases in the following order: unannealed, well dispersed $\mathrm{Pt} / \mathrm{C}, 2-3 \mathrm{~nm}$ in diameter < unannealed, poorly dispersed $\mathrm{Pt} / \mathrm{C}, 4-5 \mathrm{~nm}$ in diameter $<$ poorly dispersed $\mathrm{Pt} / \mathrm{C}, 4-5 \mathrm{~nm}$ in diameter, annealed at $900{ }^{\circ} \mathrm{C} \approx$ annealed poorly dispersed $\mathrm{PtCoC} / \mathrm{C}, 4-5 \mathrm{~nm}$ in diameter, annealed at $900{ }^{\circ} \mathrm{C}$. Clearly, subjecting the $\mathrm{Pt} / \mathrm{C}$ catalyst to a similar heat treatment as $\mathrm{PtCo} / \mathrm{C}$ provides it with the same degree of stability. It is also interesting to note that the annealed $\mathrm{Pt} / \mathrm{C}$ is much more stable than the unannealed catalyst with the same degree of dispersion. This suggests that the increased stability of the annealed sample cannot only be attributed to a larger particle size. We speculate that the annealing procedure smoothed out the surface of the catalyst to remove the defects or the undercoordinated sites most prone to corrosion.

The loss of specific activity of Pt-alloys with time, as shown in Fig. 10, is largely due to dealloying. The process of dealloying at Pt-alloy nanoparticles in PEMFCs has been studied in detail by several groups. ${ }^{149,150,161-163}$ As described earlier, the solute metal at the surface of the catalyst should dissolve at high potentials into the acidic electrolyte. Any stabilisation of the solute metal afforded by alloying would be insufficient to prevent dissolution

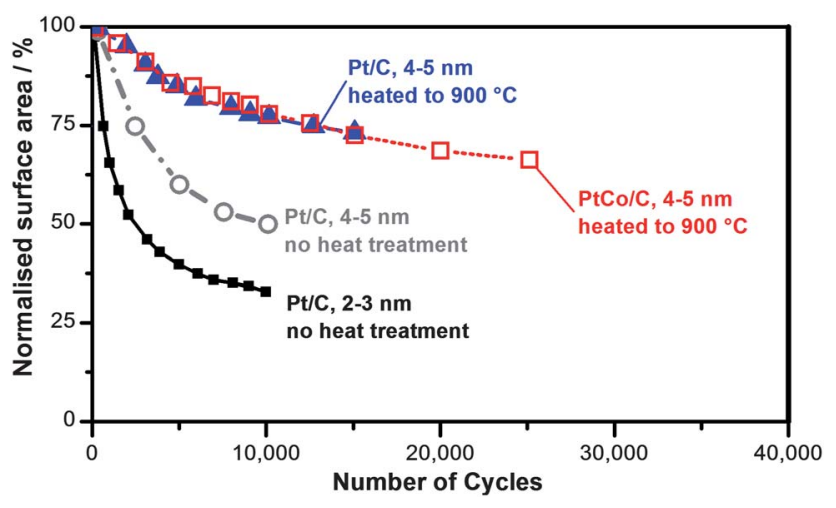

Fig. 11 Normalised surface area for different $\mathrm{Pt} / \mathrm{C}$ and $\mathrm{PtCo} / \mathrm{C}$ catalysts, upon cycling in a PEMFC between 0.6 and $1 \mathrm{~V}$ at $20 \mathrm{mV} \mathrm{s}^{-1}$ and $80^{\circ} \mathrm{C}$, adapted from Makharia et al. ${ }^{128}$ The surface area was determined by the voltammetric adsorption of hydrogen between $0.5 \mathrm{~V}$ and $0.05 \mathrm{~V}$ (see earlier footnote**). 
under these conditions. ${ }^{73,158}$ This can be rationalised on the basis that the PEMFC cathode operates at potentials far above the dissolution potentials of the solute metals in their bulk form. ${ }^{158}$ With time, the more reactive solute metal would tend to segregate to the surface. ${ }^{162-164}$ This segregation is brought about by the concentration gradient between the surface and the catalyst core. Moreover, the segregation of the solute metal from the subsurface layer to the surface layer may be accelerated by direct interactions between adsorbed $\mathrm{O}^{*}$ or $\mathrm{HO}^{*}$ and the subsurface metal ${ }^{160,165}$ (especially as $\mathrm{O}^{*}$ is usually adsorbed in a hollow site $^{28}$ ). Since the coverages of $\mathrm{HO}^{*}$ and $\mathrm{O}^{*}$ increase with potential, at high potentials, such direct interactions would be more likely. Upon reaching the surface, the solute metal atoms will dissolve into the electrolyte. Subsurface oxide formation is likely to be more problematic in the case of Pt alloys than for Pt: solute metal oxides such as $\mathrm{CoO}_{x}, \mathrm{NiO}_{x}$ or $\mathrm{CuO}_{x}$ cannot be reduced back to the metallic form under reaction conditions. ${ }^{13}$ The solute metal atoms could also reach the surface of the catalyst via dissolution of the Pt overlayer at high potentials. In summary, the propensity of a Pt-alloy nanoparticle towards solute metal dissolution, or dealloying, is determined by (a) the diffusivity of the solute metal, (b) the diffusion length of the solute metal within the nanoparticle, (c) the extent of the direct interaction between the subsurface solute metal and adsorbed $\mathrm{O}^{*}$ and $\mathrm{OH}^{*}$, and (d) the integrity of the Pt overlayer.

The other cause of degradation of the specific activity of Pt-alloys with time is Ostwald ripening. Whereas Ostwald ripening on $\mathrm{Pt} / \mathrm{C}$ results in an increase in specific activity, the converse effect can occur on Pt alloys. The dissolution of Pt from small Pt-alloy nanoparticles will cause it to redeposit onto larger nanoparticles, where it forms a thick shell on an alloy core. ${ }^{150,151}$ This reduces the solute metal content, resulting in a decrease in specific activity. Presumably this is either due to strain relaxation $^{74}$ or due to a decreased subsurface solute metal content. ${ }^{73}$

\section{Strategies to improve the performance of Pt-alloy nanoparticles}

Studies performed on extended surfaces have suggested several routes towards improving the performance of Pt by alloying. However, the perspective of implementing these strategies upon nanoparticles is often more challenging. For instance, one could anticipate that "Pt-skin" nanoparticles should exhibit improved activity over Pt in comparison to "Pt-skeleton" nanoparticles. However, surface impurities, surface segregation of the solute metal, ${ }^{160}$ sintering, ${ }^{166}$ and degradation of the carbon support ${ }^{167}$ all complicate the annealing process on nanoparticles. Nonetheless, several research groups have reported the synthesis of "Pt-skin" structures upon carbon-supported Pt-alloy nanoparticles. ${ }^{90,151,168,169}$ They achieved this either through hightemperature annealing in an inert or reducing atmosphere or by electrochemical cycling in a CO-saturated electrolyte. Each of these studies demonstrated a higher ORR activity than for a standard leached "Pt-skeleton" catalyst. In the case of Wang et al., they optimised their annealing procedure to the extent that they were able to maintain the Pt dispersion and stabilise the catalyst upon extended cycling in RDE experiments. ${ }^{169}$

Inspired by work on single crystals, some research groups have aimed to improve the ORR activity of $\mathrm{Pt}$ and Pt-alloy nanoparticles by controlling the catalyst shape. ${ }^{170-174}$ In general, as long as the measurements are conducted in a nonadsorbing electrolyte, it seems that octahedral alloy nanoparticles, dominated by (111) facets, are more active than cubes of the same composition, dominated by (100) facets. ${ }^{171-173}$ These results are in qualitative agreement with the single crystal experiments on $\mathrm{Pt}_{3} \mathrm{Ni}^{25}$ Although some of these studies reported promising mass activitites, ${ }^{173}$ they were not amongst the highest reported in the literature. ${ }^{168,169,175}$ Presumably this was due to the large particle sizes tested. Moreover, we anticipate that the well defined morphologies could be challenging to stabilise over long time periods. ${ }^{151}$

An approach pioneered by the Adzic and co-workers, but also adopted by other groups, is to form Pt overlayers onto a core containing a significant proportion of another noble metal, such as Ir, $\mathrm{Au}$ or $\mathrm{Pd}$. These include $\mathrm{Pt}$ on $\mathrm{Pd} / \mathrm{C},{ }^{143,176} \mathrm{Pt}$ on $\mathrm{PdFe} / \mathrm{C}, \mathrm{Pt}$ on $\mathrm{PdCo} / \mathrm{C},{ }^{177,178} \mathrm{Pt}$ on $\mathrm{AuFe} / \mathrm{C},{ }^{179} \mathrm{Pt}$ on $\mathrm{AuFeNi} / \mathrm{C}^{180}$ and $\mathrm{Pt}$ on $\mathrm{AuPd} / \mathrm{C} .{ }^{181}$ The most promising aspect of these catalysts is the enhanced stability that some of them exhibit. Their nominally high $\mathrm{Pt}$ mass activities are of lesser relevance: replacing the $\mathrm{Pt}$ content with another platinum group metal has no significant long term advantage in terms of cost: at the time of writing, $\mathrm{Au}$ has a higher cost than that of $\mathrm{Pt} ;{ }^{182} \mathrm{Pd}$ is currently cheaper than Pt but faces similar supply constraints. ${ }^{2}$ Nonetheless, these catalysts have shown exceptionally high stability. For instance, $\mathrm{Pt}$ on $\mathrm{FeAu} / \mathrm{C}$ only lost $\sim 7 \%$ of its initial ORR activity when cycled 60000 times between 0.6 and $1.1 \mathrm{~V}$ in an RDE experiment, ${ }^{179} \mathrm{Pt}$ on $\mathrm{AuPd} / \mathrm{C}$ only lost $37 \%$ of its initial ORR activity when cycled 100000 times between 0.6 and $1 \mathrm{~V}$ in a PEMFC. ${ }^{181}$ The high stability of these catalysts could be due to (a) the decoration of steps or other defects on $\mathrm{Pt}$ with $\mathrm{Au}$, preventing their dissolution, ${ }^{141}$ (b) that subsurface oxide formation is inhibited by the presence of Au or Ir in the subsurface layer ${ }^{179,184}$ and (c) the dissolution of Pd from the core, causing a contraction of the Pt overlayer and a decreased propensity towards dissolution. ${ }^{181}$ Future progress in the development of these novel nanostructures would be to substantially increase their mass activity, normalised to total platinum group metal content (rather than the platinum metal content), and to prepare them using a synthesis method amenable towards industrial scale-up. ${ }^{185}$

It is worth considering what the ideal configuration would be for a Pt-based ORR catalyst. The Pt overlayer would only be a single layer thick, would be at least as active as pure Pt, and the core would consist of a material that is abundant and inexpensive. Chen and coworkers recently reported that such a catalyst exists for the hydrogen evolution reaction. ${ }^{186-188}$ They found that a monolayer of Pt on WC exhibited the same hydrogen evolution activity as bulk Pt. Even so, the same catalyst exhibited poor activity for the ORR, most likely because the WC formed a $\mathrm{WO}_{x}$ phase at high potentials. ${ }^{186}$ Whereas WC has a higher surface energy than $\mathrm{Pt},{ }^{189,190} \mathrm{WO}_{x}$ has a lower surface energy. ${ }^{191}$ Such differences in surface energy between the core and the shell would drive the dissolution of $\mathrm{Pt}$ under ORR conditions. ${ }^{192}$ This example shows how challenging it is to find a Pt core-shell structure which is active for the ORR, stable and which contains an inexpensive core.

Very recently, two groups have reported an unexpected result by dealloying Pt-alloy or Pt core-shell catalysts: the formation of 


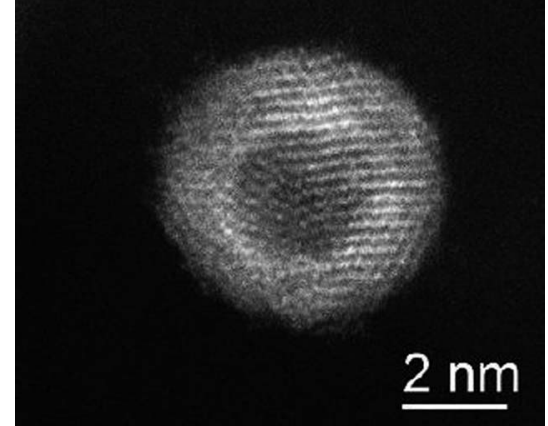

Fig. 12 TEM image of a hollow Pt nanoparticle. Reproduced with permission from Wang et al. ${ }^{183}$ Copyright 2011 American Chemical Society.

hollow Pt nanoparticles, as shown in Fig. $12 .{ }^{161,183}$ Dubau et al. subjected $\mathrm{Pt}_{3} \mathrm{Co}$ nanoparticles to 654 hours of start up and shut down cycles at a PEMFC cathode, each cycle lasting two hours. The outcome of this was that that the $\mathrm{Pt}_{3} \mathrm{Co} / \mathrm{C}$ precursors transformed into hollow Pt nanoparticles, with no measurable Co content. ${ }^{161}$ Most notably, the ORR activity of these catalysts was higher than the initial activity of the Pt-alloy, despite the lack of Co. They attributed the formation of this structure to the Kirkendall effect, whereby the outwards diffusion of Co is countered by a flux of vacancies to the core of the nanoparticle. In a parallel study, Adzic and co-workers also reported the discovery of a remarkably similar catalyst, although they started with a $\mathrm{Pt}-\mathrm{Ni} / \mathrm{C}$ core shell structure. ${ }^{183}$ In RDE experiments, the initial mass activity of their nanoparticles was $1.1 \mathrm{~A} \mathrm{mg}_{\mathrm{Pt}^{-1}}, 4.4$ times higher than that of their conventional $\mathrm{Pt} / \mathrm{C}$ catalyst. After cycling the hollow catalysts 6000 times, only $\sim 33 \%$ of the initial mass activity was lost, in comparison to a $\sim 60 \%$ loss for solid $\mathrm{Pt}$ nanoparticles. They attributed the improved activity of the hollow nanoparticles over solid $\mathrm{Pt} / \mathrm{C}$ to the compressive strain induced by a contraction of the nanoparticle surface. On the other hand, they attributed the enhanced stability to a decreased proportion of undercoordinated sites. These hollow structures are particularly promising, and could represent a new direction in ORR electrocatalysis.

\section{Alloys of Pt and early transition metals}

Given the challenges described above, we recently set about to look for new $\mathrm{Pt}_{3} X$ or $\mathrm{Pd}_{3} X$ alloys (where $X$ is another transition metal) that could be both active and stable, using a theoretical screening study. ${ }^{28}$ Our criteria for selecting the alloys were that (a) they should exhibit $\Delta G_{\mathrm{O}^{*}} \approx 0.2 \mathrm{eV}$ weaker than pure $\mathrm{Pt}$, (b) they should form Pt or Pd overlayers, (c) the oxide or hydroxide formation potential of the base metal, $X$, should be more positive than its dissolution potential, and (d) the alloy should be as stable as possible.

The main outcome of the theoretical screening study is summarised in Fig. 13a, where the descriptor for activity, $\Delta G_{\mathrm{O}^{*} \text {, is }}$ plotted as a function of the descriptor for stability, $\Delta E_{\text {alloy }}$, the alloying energy. All the previously known alloys such as $\mathrm{Pt}_{3} \mathrm{Co}$, $\mathrm{Pt}_{3} \mathrm{Ni}$ have close to the ideal value of $\Delta G_{\mathrm{O}^{*}}$ for optimal activity but have a negligible alloying energy. This could explain their propensity towards dealloying. On the other hand, two candidates in particular, $\mathrm{Pt}_{3} \mathrm{Y}$ and $\mathrm{Pt}_{3} \mathrm{Sc}$, stand out as having both the
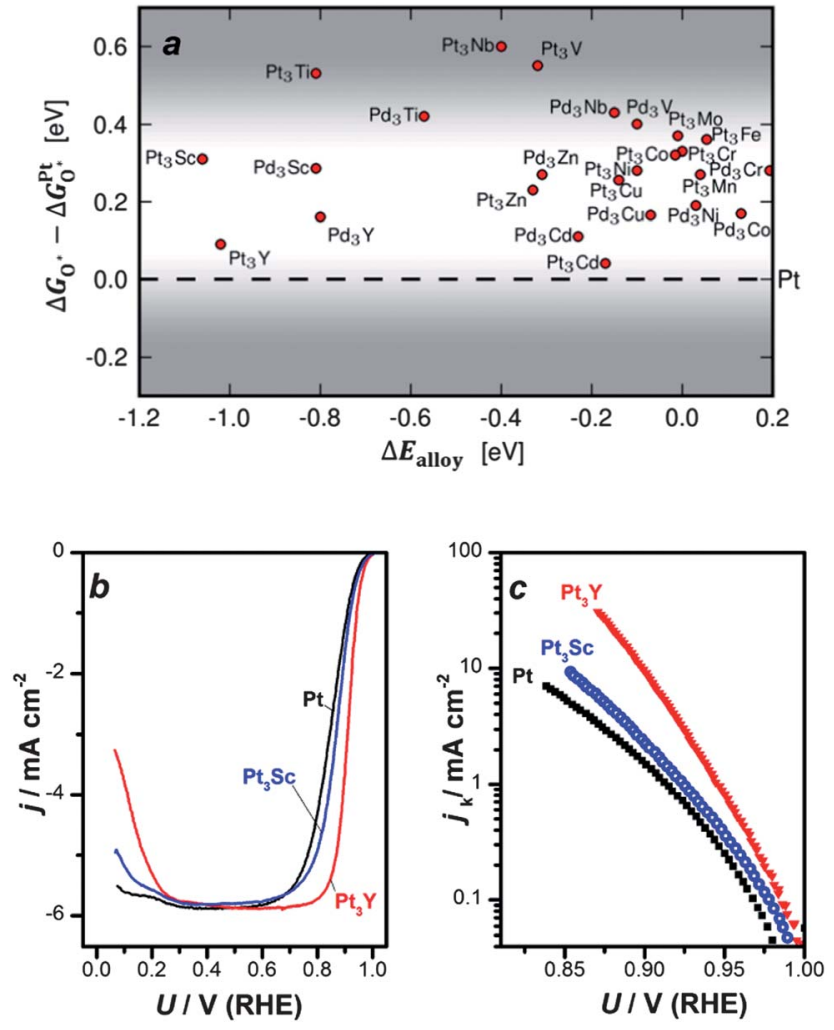

Fig. 13 (a) Output of theoretical screening study, with the descriptor for activity, $\Delta G_{\mathrm{O}^{*}}-\Delta G_{\mathrm{O}^{*}}^{\mathrm{Pt}}$, plotted as a function of the descriptor for stability, $\Delta E_{\text {alloy }}$, (b) verification of theoretical predictions, with cyclic voltammogram of sputter-cleaned polycrystalline $\mathrm{Pt}, \mathrm{Pt} 3 \mathrm{Sc}$ and $\mathrm{Pt} 3 \mathrm{Y}$ in $\mathrm{O}_{2}$-saturated $0.1 \mathrm{M} \mathrm{HClO}_{4}$ at $23{ }^{\circ} \mathrm{C}$ (only the anodic sweep is shown) and (c) a Tafel plot showing kinetic current density, $j_{\mathrm{k}}$, of sputter-cleaned polycrystalline $\mathrm{Pt}, \mathrm{Pt}_{3} \mathrm{Sc}$ and $\mathrm{Pt}_{3} \mathrm{Y}$, as a function of $U$, based on data from (b). Copyright 2009, data reproduced with permission from Macmillan Publishers Ltd. ${ }^{25}$

optimal $\Delta G_{\mathrm{O}^{*}}$ and exceptionally negative alloying energies. In fact, in a database of 60000 face-centred cubic (FCC) alloys, these compounds had the most negative values of $\Delta E_{\text {alloy }}{ }^{193,194}$

On that basis, we set about to test the promising candidates alloys experimentally. Fig. 13b shows the RDE voltammograms in $\mathrm{O}_{2}$-saturated $0.1 \mathrm{M} \mathrm{HClO}_{4}$ of sputter-cleaned, polycrystalline extended surfaces of $\mathrm{Pt}_{3} \mathrm{Y}$ and $\mathrm{Pt}_{3} \mathrm{Sc}$, in comparison to $\mathrm{Pt}$. The positive voltammetric shifts, relative to $\mathrm{Pt}$ represent significant improvements in their ORR activity. Indeed, correcting for the effects of diffusion (which are relatively insignificant in a PEMFC), $\mathrm{Pt}_{3} \mathrm{Y}$ has a $\sim 5$ fold improvement in ORR activity at $0.9 \mathrm{~V}$, and $\sim 9$ times improvement at $0.87 \mathrm{~V}$. Such high activity was unprecedented for a polycrystalline surface, especially for a sputter-cleaned and acid leached "Pt-skeleton" catalyst. ${ }^{89}$

More recently, Jong Yoo et al. obtained even higher activity upon sputter-deposited Pt-Y catalysts in an RDE assembly. ${ }^{195}$ They also demonstrated that the catalyst activity was unchanged after 3000 cycles between 0.6 and $1.1 \mathrm{~V}$. Their results confirm that this is a promising system, worthy of further investigation. The high stability of $\mathrm{Pt}_{3} \mathrm{Y}$ and $\mathrm{Pt}_{3} \mathrm{Sc}$ is characteristic of alloys of late and early transition metals. It can be understood on the basis that the half-filled metal-metal d-band in these alloys results in filled bonding states and empty 
anti-bonding states. ${ }^{193,194}$ Incidentally, this feature has resulted in the widespread utilisation of $\mathrm{Ni}_{3} \mathrm{Ti}$ superalloys in aerospace applications, due to their superior chemical and mechanical resilience at high temperatures. ${ }^{196}$ Despite the alloy stability, under the operating conditions of a PEMFC, there would be a strong thermodynamic driving force towards the dissolution of $\mathrm{Y}$ or $\mathrm{Sc}$ from $\mathrm{Pt}_{3} \mathrm{Y}$ or $\mathrm{Pt}_{3} \mathrm{Sc}$. For instance, the standard dissolution potential, $U_{0}$, for $\mathrm{Y}$ to $\mathrm{Y}^{3+}$ is $-2.372 \mathrm{~V}$ with respect to a normal hydrogen electrode (NHE) ${ }^{13}$ and the alloying energy of $\mathrm{Pt}_{3} \mathrm{Y}$ stabilises each $\mathrm{Y}$ atom by $4 \mathrm{eV}$; this means that at a potential of $1 \mathrm{~V}$, there is a driving force of $(-2.372-1) \times 3-$ $(-4)=-6.1 \mathrm{eV}$ for the dissolution of each $\mathrm{Y}$ atom. Nonetheless, the negative alloying energy would set a significantly higher barrier for solute metal diffusion in these compounds than in alloys of $\mathrm{Pt}$ with late transition metals, such as $\mathrm{Pt}_{x} \mathrm{Ni}, \mathrm{Pt}_{x} \mathrm{Co}$ or $\mathrm{Pt}_{x} \mathrm{Cu}$. We hypothesise that this could provide alloys of $\mathrm{Pt}$ and early transition metals with the kinetic stability to prevent dealloying and ensure their long term durability in a PEMFC cathode.

Following on from our promising results with $\mathrm{Pt}_{3} \mathrm{Y}$ and $\mathrm{Pt}_{3} \mathrm{Sc}$, we set about to investigate other alloys of $\mathrm{Pt}$ with early transition metals as ORR catalysts. We tested polycrystalline, sputtercleaned $\mathrm{PtY}, \mathrm{Pt}_{3} \mathrm{Zr}_{\mathrm{r}} \mathrm{Pt}_{2} \mathrm{Y}, \mathrm{Pt}_{3} \mathrm{Zr}, \mathrm{Pt}_{3} \mathrm{Hf}, \mathrm{Pt}_{5} \mathrm{Y}$ and $\mathrm{Pt}_{3} \mathrm{Y}$, using the same methodology as for the experiments shown in Fig. 13b ${ }^{41}$ The activity of the different catalysts is ranked in Fig. 14 at $0.9 \mathrm{~V}$. In the figure we also report, for the first time, the activity of $\mathrm{Pt}_{5} \mathrm{La}$. The overall ranking of catalyst activity is, in ascending order: $\mathrm{Pt}_{2} \mathrm{Y} \approx \mathrm{Pt}_{3} \mathrm{Zr} \approx \mathrm{Pt}<\mathrm{Pt}_{3} \mathrm{Hf}<\mathrm{Pt}_{3} \mathrm{Sc} \ll \mathrm{Pt}_{5} \mathrm{La} \approx \mathrm{Pt}_{5} \mathrm{Y}<$ $\mathrm{Pt}_{3} \mathrm{Y}$. We confirm that the most active catalyst within this class of $\mathrm{Pt}$ alloys is $\mathrm{Pt}_{3} \mathrm{Y}$ that we previously reported. Our XPS results suggested that $\mathrm{HfO}_{x}$ and $\mathrm{ZrO}_{x}$ formed on the surface of $\mathrm{Pt}_{3} \mathrm{Hf}$ and $\mathrm{Pt}_{3} \mathrm{Zr}$, respectively, explaining their lower activity. ${ }^{41} \mathrm{It}$ is curious to note that although $\mathrm{Pt}_{5} \mathrm{Y}$ and $\mathrm{Pt}_{5} \mathrm{La}$ exhibit lower activity than $\mathrm{Pt}_{3} \mathrm{Y}$, they are still up to 5 or 6 times as active in the potential range 0.9 to $0.87 \mathrm{~V}$, much higher than alloys such as $\mathrm{Pt}_{3} \mathrm{Co}$ and $\mathrm{Pt}_{3} \mathrm{Ni}$ prepared in a similar manner. ${ }^{197}$

In order to determine the composition of the active phase of the $\mathrm{Pt}_{5} \mathrm{La}$ catalyst, we employed angle resolved XPS to obtain a non-destructive depth profile, as shown in Fig. 15. The Pt overlayer thickness is at least $\sim 1 \mathrm{~nm}$ thick. The absence of La in the subsurface layer suggests that the effect of alloying is to strain the $\mathrm{Pt}$ overlayer. Since $\mathrm{La}$ is larger than $\mathrm{Pt},{ }^{198}$ one could

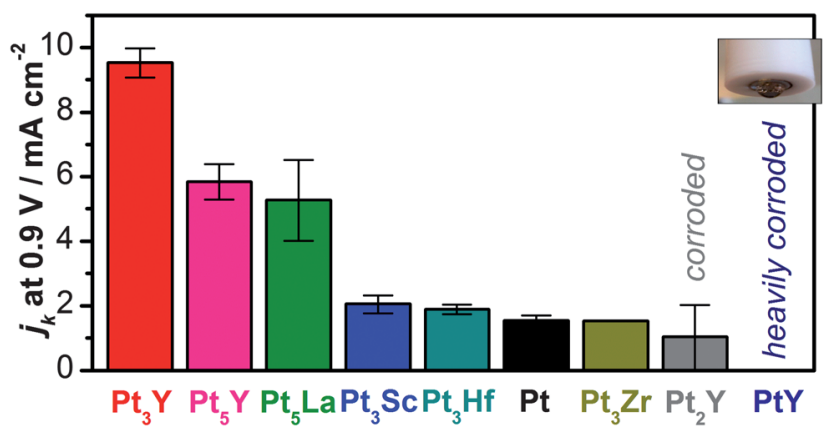

Fig. 14 Overall ranking of ORR activity, expressed as $j_{\mathrm{k}}$ for sputtercleaned polycrystalline alloys of Pt and early transition metals. All data are taken in $\mathrm{O}_{2}$-saturated $0.1 \mathrm{M} \mathrm{HClO}_{4}$ at $23^{\circ} \mathrm{C}$ and $1600 \mathrm{RPM}$, from the anodic sweep, the same conditions as in Fig. 13b. Every catalyst was reported previously, ${ }^{28,41}$ except for $\mathrm{Pt}_{5} \mathrm{La}$, which is from the current study.
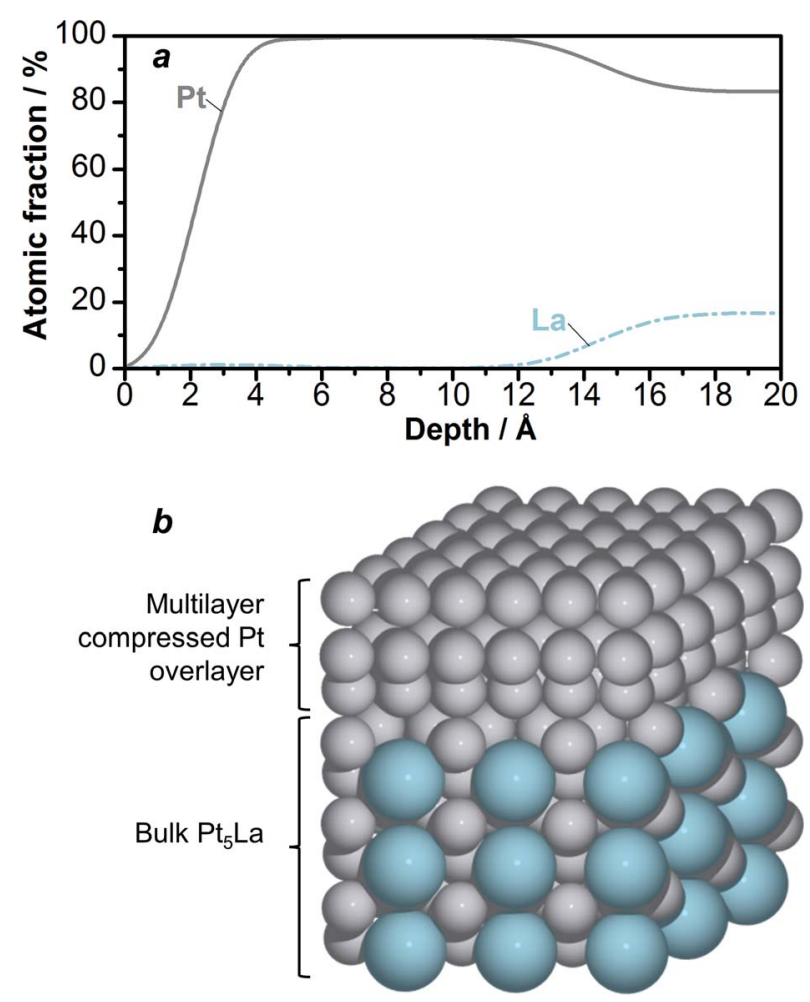

Fig. 15 (a) Non-destructive depth profile of polycrystalline, sputter cleaned, $\mathrm{Pt}_{5} \mathrm{La}$, after cycling for 90 minutes between 0 and $1 \mathrm{~V}$ in $\mathrm{O}_{2^{-}}$ saturated $0.1 \mathrm{M} \mathrm{HClO}_{4}$. The profile was constructed from an angle resolved XPS measurement, taken ex situ under UHV conditions. The adventitious $\mathrm{C}$ and $\mathrm{O}$ traces produced from airborne contamination have been omitted for clarity. (b) Schematic illustration of the structure shown in $a$, consisting of a multilayer-thick, compressed Pt overlayer covering a bulk $\mathrm{Pt}_{5} \mathrm{La}$ alloy; the grey atoms are $\mathrm{Pt}$ and the large blue atoms are La.

intuitively expect the surface to be under tensile strain, which would be the opposite of the desired effect to improve its activity. Consequently, to understand the high activity of this catalyst, we employed DFT calculations. Unlike $\mathrm{Pt}, \mathrm{Pt}_{3} \mathrm{Ni}$ or $\mathrm{Pt}_{3} \mathrm{Y}, \mathrm{Pt}_{5} \mathrm{La}$ does not form a closely packed structure in the bulk. ${ }^{199}$ The bulk structure is comprised of alternating layers of pure $\mathrm{Pt}$ and $\mathrm{Pt}$ and $\mathrm{La}$, parallel to the (001) plane, as shown schematically in Fig. 15b. The pure Pt layers have vacancies at the positions where $\mathrm{La}$ atoms lie below. However, our calculations indicate that when a Pt overlayer covers the bulk alloy, the overlayer resembles closely packed $\mathrm{Pt}$, with extra $\mathrm{Pt}$ atoms at the equivalent positions where vacancies exist in the bulk, as shown in Fig. 15b. The overlayer would then be compressed, relative to pure Pt. According to our simulations, when the thickness of the $\mathrm{Pt}$ overlayer on $\mathrm{Pt}_{5} \mathrm{La}$, is 3 monolayers thick, the adsorption energies of $\mathrm{O}^{*}$ are converged (to within $0.04 \mathrm{eV}$ ) to those of strained pure $\mathrm{Pt}(111)$, with the lateral $\mathrm{Pt}-\mathrm{Pt}$ distance set by the bulk $\mathrm{Pt}_{5} \mathrm{La}$ substrate, i.e. there is no ligand effect from La. This means that the thick Pt overlayer can be modelled as a strained pure $\mathrm{Pt}$ slab. ${ }^{97} \mathrm{On}$ that basis, we calculate the adsorption energy of $\mathrm{HO}^{*}$ in a half dissociated water layer to be $0.14 \mathrm{eV}$ weaker in comparison to unstrained Pt. This explains the high ORR activity of $\mathrm{Pt}_{5} \mathrm{La}$, as demonstrated by its position on the volcano in Fig. 5. To the best of our knowledge, this is the first time that an alloy of Pt and La has been tested for the ORR. Our DFT 
calculations show that $\mathrm{Pt}_{5} \mathrm{La}$ has an alloying energy of $-0.66 \mathrm{eV}$ atom $^{-1}$, or $-3.96 \mathrm{eV}(\mathrm{La} \text { atom })^{-1}$. Moroever, it is only one out of several alloys that $\mathrm{Pt}$ forms with lanthanides, forming stable compounds. This suggests that these compounds could be worthy of further investigation.

There are several challenges facing the implementation of $\mathrm{Pt}$ alloys with early transition metals (or lanthanides) as oxygen reduction catalysts in fuel cells. Thus far, they have only been synthesised in bulk, polycrystalline form. We anticipate that they would be particularly amenable towards sputter deposition onto a nanostructured thin film, such as that used by $3 \mathrm{M}$ (described earlier in this paper). ${ }^{105,106}$ However, large scale production would be more economically feasible if they could be synthesised in nanoparticulate form, using a chemical method.

\section{Conclusions and outlook}

In this perspective article we have reviewed the fundamentals underlying the catalysis of oxygen reduction on Pt and Pt-alloys, under conditions relevant for polymer electrolyte membrane fuel cells.

Although the ORR activity of $\mathrm{Pt}$ can be substantially enhanced by alloying, further improvements are required that will allow for (a) the high activity achieved on extended surfaces to be realised on the nanoparticulate catalysts used in a fuel cell and (b) the activity of these catalysts being stabilised for long periods of time and with extensive cycling. In summary: high activity is a necessary but insufficient criterion for an effective oxygen reduction catalyst; high dispersion and stability are also essential.

We have demonstrated how the oxygen reduction activity of Pt-alloys can be defined by the scaling relations between the intermediates, as shown in Fig. 4. Unfortunately, it turns out that the constant difference of $\sim 3.2 \mathrm{eV}$ between the binding energy of the $\mathrm{HO}^{*}$ and $\mathrm{HOO}^{*}$ intermediates not only holds for metal surfaces, but also for oxides and $\mathrm{N}$-functionalised graphitic materials. ${ }^{21,87}$ Although these relations are useful in describing known trends and can predict new metallic catalysts, they impose a limit on the extent to which the ORR can be catalysed at low overpotentials. Even so, the scaling relations might not be universal if the two-dimensional limitations considered here could be broken. Enzymes such as cytochrome c oxidase exhibit flatter free energy landscapes at the reversible potential than even the most active of man made catalysts, such as $\mathrm{Pt}_{3} \mathrm{Ni}^{200}$ Emulating these enzymes would lead to new, more efficient classes of man-made catalysts for the ORR where the stabilities of O*, $\mathrm{HO}^{*}$ and $\mathrm{HOO}^{*}$ are uncorrelated. ${ }^{70}$

\section{Experimental}

The $\mathrm{Pt}_{5} \mathrm{La}$ sample was supplied by Mateck GmbH. XRD measurements showed that it constituted a single phase, with a $\mathrm{CaCu}_{5}$ crystal prototype structure, consistent with the literature. ${ }^{199}$ Its lattice parameters are $a=5.40$ and $c=4.35$.

\section{Ultra high vacuum measurements}

In-depth surface composition information of $\mathrm{Pt}_{5} \mathrm{La}$ was extracted from angle resolved XPS spectra recorded using a Theta Probe instrument from Thermo Scientific. The chamber has a base pressure of $5 \times 10^{-10}$ mbar. The instrument uses monochromatised Al K $\alpha$ (1486.7 eV) X-rays and the electron energy analyzer has an acceptance angle of $60^{\circ}$. It facilitates XPS spectra recorded from within a diameter of $15 \mu \mathrm{m}$ with a resolution corresponding to a $\mathrm{Ag} 3 \mathrm{~d}_{5 / 2}$ full width half maximum (FWHM) smaller than $0.5 \mathrm{eV}$. The AR-XPS spectra were obtained in parallel, without tilting the sample. In consideration of the count statistics at the grazing angles, an X-ray beam size of $400 \mu \mathrm{m}$ and an energy resolution corresponding to $\sim 1.0 \mathrm{eV} \mathrm{Ag} \mathrm{3d_{5/2 }}$ FWHM was used.

The surface was sputter cleaned with a $1 \mathrm{keV}$ beam of $\mathrm{Ar}^{+}$ions, with a current of $1 \mu \mathrm{A}$, over a $7 \times 7 \mathrm{~mm}$ area. This was typically continued for around 20 minutes, until the XPS measurement indicated that impurities were negligible. The XPS spectra were taken at several different locations over the metal surfaces.

For the depth profiles, the electrons emitted at angles between $20^{\circ}$ and $80^{\circ}$ to the surface normal were analysed in parallel and detected in 16 channels corresponding to $3.75^{\circ}$ wide angle intervals. After XPS identification of the elements present at the surface, their main features were measured in detail with angle resolved XPS. The depth concentration profiles were obtained using the simulation tool, ARProcess of the Thermo Avantage software, which uses a maximum entropy method combined with a genetic algorithm. In all cases, the simulations were based on the relative intensities between Pt 4f, O 1 s and C 1 s, and La $3 \mathrm{~d}_{5 / 2}$. Further details regarding the fitting procedure are described elsewhere. ${ }^{41}$

\section{Electrochemical measurements}

All glassware was cleaned for 24 hours in a "piranha" solution consisting of a $3: 1$ mixture of $96 \% \mathrm{H}_{2} \mathrm{SO}_{4}$ and $30 \% \mathrm{H}_{2} \mathrm{O}_{2}$, followed by multiple heating and rinsing with ultrapure water $(18.2 \mathrm{M} \Omega \mathrm{cm})$ to remove sulfates. The electrochemical experiments were performed with Bio-Logic Instruments' VMP2 potentiostat, controlled by a computer. The rotating ring disk electrode (RRDE) assemblies were provided by Pine Instruments Corporation. A standard two-compartment glass cell was used, equipped with a water jacket attached to a hot water bath to control the temperature.

The electrolyte, $0.1 \mathrm{M} \mathrm{HClO}_{4}$ (Merck Suprapur), was prepared with ultrapure water. The counter electrode was a high surface area $\mathrm{Pt}$ mesh. The reference was a $\mathrm{Hg} / \mathrm{Hg}_{2} \mathrm{SO}_{4}$ electrode, separated from the working electrode compartment using ceramic frits. All potentials are quoted with respect to the reversible hydrogen electrode (RHE), and are corrected for Ohmic losses. Following each measurement, $0 \mathrm{~V}$ RHE was established by carrying out the hydrogen oxidation and hydrogen evolution reaction on $\mathrm{Pt}$ in the same electrolyte. The Ohmic drop was measured by carrying out an impedance spectrum with a peak-topeak amplitude of $10 \mathrm{mV}$, typically from $500 \mathrm{kHz}$ down to $100 \mathrm{~Hz}$. The target resistance was evaluated from the high frequency intercept on the horizontal (real) axis of the Nyquist plot and further checked by fitting the impedance spectra using EIS Spectrum Analyser software. ${ }^{201}$ Typically the uncompensated resistance came to $\sim 25 \Omega$. The RRDE was immersed into the cell under potential control at $0.05 \mathrm{~V}$ into a $\mathrm{N}_{2}$ (N5, Air Products) saturated electrolyte. The ORR activity measurements were conducted in an electrolyte saturated with $\mathrm{O}_{2}$ (N55, Air Products). 


\section{Theoretical calculations}

The surface of the $\mathrm{Pt} / \mathrm{Pt}_{5} \mathrm{La}$ was modelled by a Pt-slab with a nearest-neighbour distance similar to what is found (calculated) in Pt-layers on top of $\mathrm{Pt}_{5} \mathrm{La}$. This allowed us to model the structure of water to approximate that on $\mathrm{Pt}(111)$. It is also justified by the XPS results showing $\sim 4$ monolayers of $\mathrm{Pt}$ covering the $\mathrm{Pt}_{5} \mathrm{La}$ alloy, as shown in Fig. 15a.

In the DFT calculations, the Pt (111) surface is modelled by a slab with 6 close-packed layers, where the three topmost layers and the adsorbates are allowed to relax. The ionic cores are described by PAW setups, ${ }^{202}$ and the Kohn-Sham valence states are described on a real-space grid with a spacing of $0.18 \AA$. Exchange and correlation effects are described by the RPBE functional. $^{203}$ The Kohn-Sham Hamiltonian is diagonalized iteratively using Pulay mixing of the density and Fermi-Dirac occupation of one-electron states with $k_{\mathrm{B}} T=0.1 \mathrm{eV}$. Total energies are extrapolated to $k_{\mathrm{B}} T=0 \mathrm{eV}$. The periodic images of the slab are separated by $20 \AA$ of vacuum. All calculations have been carried out with the ASE and GPAW software packages. $^{204,205}$

The adsorption energies are calculated in a $(3 \times 2)$ surface unit cell, and the Brillouin zone is sampled by an $8 \times 8 \times 1 k$-point grid. The slab is relaxed using the quasi-Newton scheme until the maximum force component is less than $0.05 \mathrm{eV}^{-1}$.

The effect of solvation is included for $\mathrm{HO}^{*}$ by incorporating the adsorbate in an $\mathrm{H}_{2} \mathrm{O} / \mathrm{H}_{2} \mathrm{O}^{*}$ superstructure with $2 / 3 \mathrm{ML}$ total coverage. The energy of $\mathrm{HO}^{*}$ is calculated from the $\mathrm{H}_{2} \mathrm{O} / \mathrm{HO}^{*}$ configuration which minimizes the average $\mathrm{OH}$ energy. The adsorption energy of $\mathrm{H}_{2} \mathrm{O}^{*}$ is calculated in a similar superstructure with $2 / 3 \mathrm{ML}$ total coverage. In the $\mathrm{H}_{2} \mathrm{O} * / \mathrm{HO}^{*}$ superstructure, half of the water molecules lie in a plane approximately parallel to the surface, and the other water molecules lie in a plane perpendicular to the surface with one hydrogen atom pointing away from the surface..$^{61,206-210}$

\section{Acknowledgements}

Funding by the Danish Council for Technology and Innovation's FTP program and by the Danish Strategic Research Council's HyCycle programme is gratefully acknowledged. ASB acknowledges additional financial support from the European Union and the MWIFT-NRW (Hightech.NRW competition). The Center for Atomic-scale Materials Design is supported by the Lundbeck Foundation. The Center for Individual Nanoparticle Functionality is supported by the Danish National Research Foundation. The authors would like to thank Lisa Haglund for designing Fig. 3 and Simon Hedegaard Brodersen for assistance in producing the image of a $\mathrm{Pt}_{3} \mathrm{Y}$ nanoparticle.

\section{Notes and references}

1 H. A. Gasteiger, D. R. Baker and R. N. Carter, in Hydrogen Fuel Cells: Fundamentals and Applications, Wiley-CPH, 2010.

2 Platinum 2011 Interim Review, http://www.platinum.matthey.com/ uploaded_files/Int_2011/platinum_book_complete_publication.pdf, accessed 11 December, 2011.

3 Organization of Motor Vehicle Manufacturers 2010 Production Statistics, http://www.oica.net/category/production-statistics/, accessed 13 February, 2012

4 J. Tollefson, Nature, 2007, 450, 334-335.
5 K. C. Neyerlin, W. B. Gu, J. Jorne and H. A. Gasteiger, J. Electrochem. Soc., 2007, 154, B631-B635.

6 F. T. Wagner, B. Lakshmanan and M. F. Mathias, J. Phys. Chem. Lett., 2010, 1, 2204-2219.

7 H. A. Gasteiger, S. S. Kocha, B. Sompalli and F. T. Wagner, Appl. Catal., B, 2005, 56, 9-35.

8 G. M. Whitesides and G. W. Crabtree, Science, 2007, 315, 796.

9 L. C. Gontard, R. E. Dunin-Borkowski and D. Ozkaya, J. Microsc., 2008, 232, 248-259.

10 L. C. Gontard, L. Y. Chang, C. J. D. Hetherington, A. I. Kirkland, D. Ozkaya and R. E. Dunin-Borkowski, Angew. Chem., Int. Ed., 2007, 46, 3683-3685.

11 Y. Shao-Horn, W. C. Sheng, S. Chen, P. J. Ferreira, E. F. Holby and D. Morgan, Top. Catal., 2007, 46, 285-305.

12 R. Borup, J. Meyers, B. Pivovar, Y. S. Kim, R. Mukundan, N. Garland, D. Myers, M. Wilson, F. Garzon, D. Wood, P. Zelenay, K. More, K. Stroh, T. Zawodzinski, J. Boncella, J. E. McGrath, M. Inaba, K. Miyatake, M. Hori, K. Ota, Z. Ogumi, S. Miyata, A. Nishikata, Z. Siroma, Y. Uchimoto, K. Yasuda, K. I. Kimijima and N. Iwashita, Chem. Rev., 2007, 107, 3904-3951.

13 M. Pourbaix, Atlas of Electrochemical Equilibria in Aqueous Solutions, National Association of Corrosion Engineers, Houston, Texas, 1974.

14 R. Bashyam and P. Zelenay, Nature, 2006, 443, 63-66.

15 M. S. Thorum, J. Yadav and A. A. Gewirth, Angew. Chem., Int. Ed., 2009, 48, 165-167.

16 E. I. Solomon, U. M. Sundaram and T. E. Machonkin, Chem. Rev., 1996, 96, 2563-2605.

17 F. A. Armstrong and J. Hirst, Proc. Natl. Acad. Sci. U. S. A., 2011, 108, 14049-14054.

18 Y. Gorlin and T. F. Jaramillo, J. Am. Chem. Soc., 2010, 132, 1361213614

19 J. Suntivich, H. A. Gasteiger, N. Yabuuchi and Y. Shao-Horn, J. Electrochem. Soc., 2010, 157, B1263-B1268.

20 M. Lefevre, E. Proietti, F. Jaouen and J. P. Dodelet, Science, 2009, 324, 71-74.

21 F. Calle-Vallejo, J. I. Martinez and J. Rossmeisl, Phys. Chem. Chem. Phys., 2011, 13, 15639-15643.

22 G. Wu, K. L. More, C. M. Johnston and P. Zelenay, Science, 2011, 332, 443-447.

23 H. A. Gasteiger and N. M. Markovic, Science, 2009, 324, 48-49.

$24 \mathrm{H}$. A. Gasteiger and J. Garche, in Handbook of Heterogeneous Catalysis, ed. G. Ertl, H. Knoezinger, F. Schueth and J. Weitkamp, Wiley-CPH, Chichester, 2nd edn, 2008, pp. 3081-3120.

25 V. R. Stamenkovic, B. Fowler, B. S. Mun, G. F. Wang, P. N. Ross, C. A. Lucas and N. M. Markovic, Science, 2007, 315, 493-497.

26 V. Stamenkovic, B. S. Mun, K. J. J. Mayrhofer, P. N. Ross, N. M. Markovic, J. Rossmeisl, J. Greeley and J. K. Nørskov, Angew. Chem., Int. Ed., 2006, 45, 2897-2901.

27 T. Toda, H. Igarashi, H. Uchida and M. Watanabe, J. Electrochem. Soc., 1999, 146, 3750-3756.

28 J. Greeley, I. E. L. Stephens, A. S. Bondarenko, T. P. Johansson, H. A. Hansen, T. F. Jaramillo, J. Rossmeisl, I. Chorkendorff and J. K. Nørskov, Nat. Chem., 2009, 1, 552-556.

29 R. R. Adzic, J. Zhang, K. Sasaki, M. B. Vukmirovic, M. Shao, J. X. Wang, A. U. Nilekar, M. Mavrikakis, J. A. Valerio and F. Uribe, Top. Catal., 2007, 46, 249-262.

30 S. Mukerjee, S. Srinivasan, M. P. Soriaga and J. McBreen, $J$. Electrochem. Soc., 1995, 142, 1409-1422.

31 P. N. Ross, Report EM-1553, Electric Power Research Institute, Palo Alto, California, 1980.

32 V. Jalan and D. A. Landsman, US Pat., US4186110-A, 1979.

33 D. A. Landsman and F. J. Luczak, US Pat., US4316944-A, 1981.

34 S. Mukerjee and S. Srinivasan, J. Electroanal. Chem., 1993, 357, 201-224.

35 S. Mukerjee and J. McBreen, J. Electroanal. Chem., 1998, 448, $163-$ 171.

36 D. Thompsett, in Handbook of Fuel Cells, ed. W. Vielstich, H. A. Gasteiger and H. Yokakawa, John Wiley \& Sons, Ltd, Chichester, 2003, vol. 3, p. 467.

37 M. F. Matthias, R. Makharia, H. A. Gasteiger, J. J. Conley, T. F. Fuller, C. J. Gittleman, S. S. Kocha, D. P. Miller, C. K. Mittelsteadt, T. Xie, S. G. Yan and T. Y. Yu, Interface, $2005,14,24-35$. 
38 U. Eberle and R. von Helmolt, Energy Environ. Sci., 2010, 3, 689699.

39 C.-J. Yang, Energy Policy, 2009, 37, 1805-1808.

40 Y. Sun, M. Delucchi and J. Ogden, Int. J. Hydrogen Energy, 2011, 36, 11116-11127.

41 I. E. L. Stephens, A. S. Bondarenko, L. Bech and I. Chorkendorff, Chem CatChem, 2012, 4, 341-349.

42 A. A. Gewirth and M. S. Thorum, Inorg. Chem., 2010, 49, 35573566.

43 A. S. Bondarenko, I. E. L. Stephens, H. A. Hansen, F. J. PérezAlonso, V. Tripkovic, T. P. Johansson, J. Rossmeisl, J. K. Nørskov and I. Chorkendorff, Langmuir, 2011, 27, 2058-2066.

44 A. B. Anderson and T. V. Albu, J. Am. Chem. Soc., 1999, 121, $11855-11863$.

45 J. S. Filhol and M. Neurock, Angew. Chem., Int. Ed., 2006, 45, 402406.

46 A. U. Nilekar and M. Mavrikakis, Surf. Sci., 2008, 602, L89-L94.

47 O. Sugino, I. Hamada, M. Otani, Y. Morikawa, T. Ikeshoji and Y. Okamoto, Surf. Sci., 2007, 601, 5237-5240.

48 T. E. Shubina and M. T. M. Koper, Electrochem. Commun., 2006, 8, 703-706.

49 P. Vassilev, R. A. van Santen and M. T. M. Koper, J. Chem. Phys., 2005, 122, 1-12.

50 A. Roudgar and A. Gross, Chem. Phys. Lett., 2005, 409, 157-162.

51 E. Skulason, V. Tripkovic, M. E. Bjorketun, S. Gudmundsdottir, G. Karlberg, J. Rossmeisl, T. Bligaard, H. Jonsson and J. K. Nørskov, J. Phys. Chem. C, 2010, 114, 18182-18197.

52 V. Tripkovic, E. Skúlason, S. Siahrostami, J. K. Nørskov and J. Rossmeisl, J. Electrochem. Soc., 2010, 55, 7975-7981.

53 J. Rossmeisl, E. Skulason, M. E. Bjorketun, V. Tripkovic and J. K. Nørskov, Chem. Phys. Lett., 2008, 466, 68-71.

54 S. Venkatchalam and T. Jacob, in Handbook of Fuel Cells, ed. W. Vielstich, H. A. Gasteiger and H. Yokakawa, John Wiley \& Sons, Ltd, Chichester, 2009, vol. 5, pp. 133-151.

55 J. K. Nørskov, J. Rossmeisl, A. Logadottir, L. Lindqvist, J. R. Kitchin, T. Bligaard and H. Jonsson, J. Phys. Chem. B, 2004, 108, 17886-17892.

56 P. Nieto, E. Pijper, D. Barredo, G. Laurent, R. A. Olsen, E. J. Baerends, G. J. Kroes and D. Farias, Science, 2006, 312, 86-89.

57 J. K. Nørskov, T. Bligaard, A. Logadottir, S. Bahn, L. B. Hansen, M. Bollinger, H. Bengaard, B. Hammer, Z. Sljivancanin, M. Mavrikakis, Y. Xu, S. Dahl and C. J. H. Jacobsen, J. Catal., 2002, 209, 275-278.

58 K. Reuter, D. Frenkel and M. Scheffler, Phys. Rev. Lett., 2004, 93, 116105 .

59 K. Honkala, A. Hellman, I. N. Remediakis, A. Logadottir, A. Carlsson, S. Dahl, C. H. Christensen and J. K. Nørskov, Science, 2005, 307, 555-558.

60 G. S. Karlberg, J. Rossmeisl and J. K. Nørskov, Phys. Chem. Chem. Phys., 2007, 9, 5158-5161.

61 J. Rossmeisl, G. S. Karlberg, T. Jaramillo and J. K. Nørskov, Faraday Discuss., 2008, 140, 337-346.

62 M. J. Janik, C. D. Taylor and M. Neurock, J. Electrochem. Soc., 2009, 156, B126-B135.

63 J. K. Nørskov, T. Bligaard, B. Hvolbaek, F. Abild-Pedersen, I. Chorkendorff and C. H. Christensen, Chem. Soc. Rev., 2008, 37, 2163-2171.

64 J. Rossmeisl, A. Logadottir and J. K. Nørskov, Chem. Phys., 2005, 319, 178-184.

65 J. Greeley, J. Rossmeisl, A. Hellman and J. K. Nørskov, Z. Phys Chem., 2007, 221, 1209-1220.

66 P. Atkins, Physical Chemistry, W.H. Freemen \& Company, 1997.

67 H. A. Hansen, PhD thesis, Technical University of Denmark, 2009.

68 J. K. Nørskov, T. Bligaard, A. Logadottir, J. R. Kitchin, J. G. Chen, S. Pandelov and U. Stimming, J. Electrochem. Soc., 2005, 152, J23J26.

69 H. A. Hansen, I. C. Man, F. Studt, F. Abild-Pedersen, T. Bligaard and J. Rossmeisl, Phys. Chem. Chem. Phys., 2009, 12, 283-290.

70 M. T. M. Koper, J. Electroanal. Chem., 2011, 660, 254-260.

71 J. L. Zhang, M. B. Vukmirovic, Y. Xu, M. Mavrikakis and R. R. Adzic, Angew. Chem., Int. Ed., 2005, 44, 2132-2135.

72 W. P. Zhou, X. F. Yang, M. B. Vukmirovic, B. E. Koel, J. Jiao, G. W. Peng, M. Mavrikakis and R. R. Adzic, J. Am. Chem. Soc., 2009, 131, 12755-12762.
73 I. E. L. Stephens, A. S. Bondarenko, F. J. Pérez-Alonso, F. CalleVallejo, L. Bech, T. P. Johansson, A. K. Jepsen, R. Frydendal, B. P. Knudsen, J. Rossmeisl and I. Chorkendorff, J. Am. Chem. Soc., 2011, 133, 5485-5491.

74 P. Strasser, S. Koh, T. Anniyev, J. Greeley, K. More, C. F. Yu, Z. C. Liu, S. Kaya, D. Nordlund, H. Ogasawara, M. F. Toney and A. Nilsson, Nat. Chem., 2010, 2, 454-460.

75 W. P. Zhou, X. F. Yang, M. B. Vukmirovic, B. E. Koel, J. Jiao, G. W. Peng, M. Mavrikakis and R. R. Adzic, J. Am. Chem. Soc., 2009, 131, 12755-12762.

76 F. Abild-Pedersen, J. Greeley, F. Studt, J. Rossmeisl, T. R. Munter, P. G. Moses, E. Skulason, T. Bligaard and J. K. Nørskov, Phys. Rev. Lett., 2007, 99, 016105.

77 P. Sabatier, Ber. Dtsch. Chem. Ges., 1911, 44, 1984-2001.

78 A. Logadottir, T. H. Rod, J. K. Nørskov, B. Hammer, S. Dahl and C. J. H. Jacobsen, J. Catal., 2001, 197, 229-231.

79 T. Bligaard, J. K. Nørskov, S. Dahl, J. Matthiesen, C. H. Christensen and J. Sehested, J. Catal., 2004, 224, 206-217.

80 P. Ferrin, A. U. Nilekar, J. Greeley, M. Mavrikakis and J. Rossmeisl, Surf. Sci., 2008, 602, 3424-3431.

81 L. C. Grabow and M. Mavrikakis, Angew. Chem., Int. Ed., 2008, 47, $7390-7392$.

82 J. K. Nørskov, T. Bligaard, J. Rossmeisl and C. H. Christensen, Nat. Chem., 2009, 1, 37-46.

83 D. A. Hansgen, D. G. Vlachos and J. G. G. Chen, Nat. Chem., 2010, 2, 484-489.

84 M. Neurock, Ind. Eng. Chem. Res., 2010, 49, 10183-10199.

85 R. Parsons, Trans. Faraday Soc., 1958, 54, 1053-1063.

86 S. Trasatti, J. Electroanal. Chem., 1972, 39, 163.

87 I. C. Man, H.-Y. Su, F. Calle-Vallejo, H. A. Hansen, J. I. Martínez, N. G. Inoglu, J. Kitchin, T. F. Jaramillo, J. K. Nørskov and J. Rossmeisl, ChemCatChem, 2011, 3, 1159-1165.

88 J. Greeley and J. K. Nørskov, J. Phys. Chem. C, 2009, 113, 49324939.

89 V. R. Stamenkovic, B. S. Mun, K. J. J. Mayrhofer, P. N. Ross and N. M. Markovic, J. Am. Chem. Soc., 2006, 128, 8813-8819.

90 S. Chen, W. C. Sheng, N. Yabuuchi, P. J. Ferreira, L. F. Allard and Y. Shao-Horn, J. Phys. Chem. C, 2009, 113, 1109-1125.

91 C. Wang, M. F. Chi, G. F. Wang, D. van der Vliet, D. G. Li, K. More, H. H. Wang, J. A. Schlueter, N. M. Markovic and V. R. Stamenkovic, Adv. Funct. Mater., 2011, 21, 147-152.

92 L. J. Wan, T. Moriyama, M. Ito, H. Uchida and M. Watanabe, Chem. Commun., 2002, 58-59.

93 Y. Gauthier, Y. Joly, R. Baudoing and J. Rundgren, Phys. Rev. B: Condens. Matter Mater. Phys., 1985, 31, 6216-6218.

94 T. Bligaard and J. K. Nørskov, Electrochim. Acta, 2007, 52, 55125516.

95 J. R. Kitchin, J. K. Nørskov, M. A. Barteau and J. G. Chen, J. Chem. Phys., 2004, 120, 10240-10246.

96 M. Mavrikakis, B. Hammer and J. K. Nørskov, Phys. Rev. Lett., 1998, 81, 2819-2822.

97 M. Lischka, C. Mosch and A. Gross, Electrochim. Acta, 2007, 52, 2219-2228.

98 H. E. Hoster, O. B. Alves and M. T. M. Koper, ChemPhysChem, 2010, 11, 1518-1524.

99 B. Fowler, C. A. Lucas, A. Omer, G. Wang, V. R. Stamenkovic and N. M. Markovic, Electrochim. Acta, 2008, 53, 6076-6080.

100 U. Bardi, B. C. Beard and P. N. Ross, J. Catal., 1990, 124, 22-29.

101 J. Knudsen, A. U. Nilekar, R. T. Vang, J. Schnadt, E. L. Kunkes, J. A. Dumesic, M. Mavrikakis and F. Besenbacher, J. Am. Chem. Soc., 2007, 129, 6485-6490.

102 K. J. J. Mayrhofer, D. Strmcnik, B. B. Blizanac, V. Stamenkovic, M. Arenz and N. M. Markovic, Electrochim. Acta, 2008, 53, 31813188.

103 M. Watanabe, Y. M. Zhu and H. Uchida, J. Phys. Chem. B, 2000, 104, 1762-1768.

104 K. J. Andersson, F. Calle-Vallejo, J. Rossmeisl and I. Chorkendorff, J. Am. Chem. Soc., 2009, 131, 2404-2407.

105 M. K. Debe, A. K. Schmoeckel, G. D. Vernstrom and R. Atanasoski, J. Power Sources, 2006, 161, 1002-1011.

106 A. Bonakdarpour, K. Stevens, G. D. Vernstrom, R. Atanasoski, A. K. Schmoeckel, M. K. Debe and J. R. Dahn, Electrochim. Acta, 2007, 53, 688-694.

107 U. A. Paulus, T. J. Schmidt, H. A. Gasteiger and R. J. Behm, J. Electroanal. Chem., 2001, 495, 134-145. 
108 Y. Garsany, O. A. Baturina, K. E. Swider-Lyons and S. S. Kocha, Anal. Chem., 2010, 82, 6321-6328.

109 G. A. Tritsaris, J. Greeley, J. Rossmeisl and J. K. Nørskov, Catal. Lett., 2011, 141, 909-913.

110 M. H. Shao, A. Peles and K. Shoemaker, Nano Lett., 2011, 11, 3714 3719.

111 M. Nesselberger, S. Ashton, J. C. Meier, I. Katsounaros, K. J. J. Mayrhofer and M. Arenz, J. Am. Chem. Soc., 2011, 133, 17428-17433.

112 Z. Yang, S. Ball, D. Condit and M. Gummalla, J. Electrochem. Soc., 2011, 158, B1439-B1445.

113 F. Maillard, S. Pronkin and E. R. Savinova, in Handbook of Fuel Cells, John Wiley \& Sons, Ltd, 2010.

114 F. J. Perez-Alonso, D. McCarthy, A. Nierhoff, P. HernandezFernandez, C. Strebel, I. E. L. Stephens, J. H. Nielsen and I. Chorkendorff, Angew. Chem., Int. Ed., 2012, DOI: 10.1002/ anie.201200586.

115 M. D. Macia, J. M. Campina, E. Herrero and J. M. Feliu, J. Electroanal. Chem., 2004, 564, 141-150.

116 A. Kuzume, E. Herrero and J. M. Feliu, J. Electroanal. Chem., 2007, 599, 333-343.

117 J. Clavilier, A. Rodes, K. Elachi and M. A. Zamakhchari, J. Chim. Phys. Phys.-Chim. Biol., 1991, 88, 1291-1337.

118 V. Climent, N. García-Araez, E. Herrero and J. Feliu, Russ. J. Electrochem., 2006, 42, 1145-1160.

119 N. Hoshi, M. Nakamura, O. Sakata, A. Nakahara, K. Naito and H. Ogata, Langmuir, 2011, 27, 4236-4242.

120 G. S. Karlberg and G. Wahnstrom, J. Chem. Phys., 2005, 122, 194705.

121 P. J. Ferreira, G. J. la O', Y. Shao-Horn, D. Morgan, R. Makharia, S. Kocha and H. A. Gasteiger, J. Electrochem. Soc., 2005, 152, A2256-A2271.

122 M. Inaba, ECS Trans., 2009, 25, 573-581.

123 K. Hartl, M. Hanzlik and M. Arenz, Energy Environ. Sci., 2011, 4, 234-238.

124 K. G. Gallagher, R. M. Darling and T. F. Fuller, in Handbook of Fuel Cells: Advances in Electrocatalysis, Materials, Diagnostics and Durability, ed. W. Vielstich, H. A. Gasteiger and H. Yokakawa, John Wiley \& Sons, Chichester, 2009, vol. 6, pp. $820-828$.

125 L. Tang, B. Han, K. Persson, C. Friesen, T. He, K. Sieradzki and G. Ceder, J. Am. Chem. Soc., 2010, 132, 596-600.

126 L. Tang, X. Li, R. C. Cammarata, C. Friesen and K. Sieradzki, J. Am. Chem. Soc., 2010, 132, 11722-11726.

127 E. F. Holby, W. Sheng, Y. Shao-Horn and D. Morgan, Energy Environ. Sci., 2009, 2, 865-871.

128 R. Makharia, S. Kocha, P. Yu, M. A. Sweikart, W. Gu, F. Wagner and H. A. Gasteiger, ECS Trans., 2006, 1, 3-18.

129 F. J. Perez-Alonso, C. F. Elkjær, S. S. Shim, B. L. Abrams, I. E. L. Stephens and I. Chorkendorff, J. Power Sources, 2011, 196, 6085-6091.

130 R. M. Darling and J. P. Meyers, J. Electrochem. Soc., 2003, 150, A1523-A1527.

131 K. Kinoshita, J. Lundquist and P. Stonehart, J. Electroanal. Chem., 1973, 48, 157-166.

132 S. G. Rinaldo, J. Stumper and M. Eikerling, J. Phys. Chem. C, 2010 114, 5773-5785.

133 D. C. Johnson, D. T. Napp and S. Bruckenstein, Electrochim. Acta, 1970, 15, 1493-1509.

134 S. Kawahara, S. Mitsushima, K. Ota and N. Kamiya, ECS Trans., 2006, 3, 625-631.

135 R. M. Darling and J. P. Meyers, J. Electrochem. Soc., 2005, 152, A242-A247.

136 R. Jinnouchi, E. Toyoda, T. Hatanaka and Y. Morimoto, J. Phys. Chem. C, 2010, 114, 17557-17568.

137 K. Itaya, S. Sugawara, K. Sashikata and N. Furuya, J. Vac. Sci. Technol., A, 1990, 8, 515-519.

138 K. Sashikata, N. Furuya and K. Itaya, J. Vac. Sci. Technol., B. Microelectron. Nanometer Struct.-Process., Meas., Phenom., 1991, 9, 457-464

139 M. Wakisaka, S. Asizawa, H. Uchida and M. Watanabe, Phys. Chem. Chem. Phys., 2010, 12, 4184-4190.

140 M. Matsumoto, T. Miyazaki and H. Imai, J. Phys. Chem. C, 2011 , 115, 11163-11169.

141 J. Greeley, Electrochim. Acta, 2010, 55, 5545-5550.
142 H. Angerstein-Kozlowska, B. E. Conway and W. B. A. Sharp, J. Electroanal. Chem., 1973, 43, 9-36.

143 J. Zhang, Y. Mo, M. B. Vukmirovic, R. Klie, K. Sasaki and R. R. Adzic, J. Phys. Chem. B, 2004, 108, 10955-10964.

144 A. Teliska, W. E. O'Grady and D. E. Ramaker, J. Phys. Chem. B, 2005, 109, 8076-8084.

145 M. Tada, S. Murata, T. Asakoka, K. Hiroshima, K. Okumura, H. Tanida, T. Uruga, H. Nakanishi, S. Matsumoto, Y. Inada, M. Nomura and Y. Iwasawa, Angew. Chem., Int. Ed., 2007, 46, $4310-4315$.

146 H. Imai, K. Izumi, M. Matsumoto, Y. Kubo, K. Kato and Y. Imai, J. Am. Chem. Soc., 2009, 131, 6293-6300.

147 D. Friebel, D. J. Miller, C. P. O'Grady, T. Anniyev, J. Bargar, U. Bergmann, H. Ogasawara, K. T. Wikfeldt, L. G. M. Pettersson and A. Nilsson, Phys. Chem. Chem. Phys., 2011, 13, 262-266.

148 P. K. Sinha, W. Gu, A. Kongkanand and E. Thompson, J. Electrochem. Soc., 2011, 158, B831-B840.

149 K. C. Neyerlin, R. Srivastava, C. Yu and P. Strasser, J. Power Sources, 2009, 186, 261-267.

150 S. Chen, H. A. Gasteiger, K. Hayakawa, T. Tada and Y. Shao-Horn, J. Electrochem. Soc., 2010, 157, A82-A97.

151 H. L. L. Xin, J. A. Mundy, Z. Y. Liu, R. Cabezas, R. Hovden, L. F. Kourkoutis, J. L. Zhang, N. P. Subramanian, R. Makharia, F. T. Wagner and D. A. Muller, Nano Lett., 2012, 12, 490-497.

152 P. Yu, M. Pemberton and P. Plasse, J. Power Sources, 2005, 144, 1120.

153 P. Mani, R. Srivastava and P. Strasser, J. Phys. Chem. C, 2008, 112, 2770-2778.

154 S. C. Ball, B. Theobald, D. Thompsett and S. Hudson, ECS Trans., 2006, 1, 141-152.

155 S. C. Ball, S. L. Hudson, B. R. C. Theobald and D. Thompsett, ECS Trans., 2007, 11, 1267-1278.

156 F. T. Wagner, S. G. Yan and P. T. Yu, in Handbook of Fuel Cells: Advances in Electrocatalysis, Materials, Diagnostics and Durability, ed. W. Vielstich, H. A. Gasteiger and H. Yokakawa, John Wiley \& Sons, Chichester, 2009, vol. 5, pp. 250-263.

157 R. Escudero-Cid, P. Hernández-Fernández, J. C. Pérez-Flores, S. Rojas, S. Garcia-Rodríguez, E. Fatás and P. Ocón, Int. J. Hydrogen Energy, DOI: 10.1016/j.ijhydene.2011.12.158, in press.

158 J. Greeley and J. K. Nørskov, Electrochim. Acta, 2007, 52, 58295836.

159 C. A. Menning and J. G. Chen, Top. Catal., 2010, 53, 338-347.

160 C. A. Menning and J. G. Chen, J. Chem. Phys., 2009, 130, 174709

161 L. Dubau, J. Durst, F. Maillard, L. Guétaz, M. Chatenet, J. André and E. Rossinot, Electrochim. Acta, 2011, 56, 10658-10667.

162 L. Dubau, F. Maillard, M. Chatenet, J. Andre and E. Rossinot, Electrochim. Acta, 2010, 56, 776-783.

163 F. Maillard, L. Dubau, J. Durst, M. Chatenet, J. Andre and E. Rossinot, Electrochem. Commun., 2010, 12, 1161-1164.

164 K. J. J. Mayrhofer, K. Hartl, V. Juhart and M. Arenz, J. Am. Chem. Soc., 2009, 131, 16348.

165 C. A. Menning and J. G. Chen, J. Power Sources, 2010, 195, 31403144.

166 S. B. Simonsen, I. Chorkendorff, S. Dahl, M. Skoglundh, J. Sehested and S. Helveg, J. Am. Chem. Soc., 2010, 132, 7968-7975.

167 S. Murphy, R. M. Nielsen, C. Strebel, M. Johansson and J. H. Nielsen, Carbon, 2011, 49, 376-385.

168 K. J. J. Mayrhofer, V. Juhart, K. Hartl, M. Hanzlik and M. Arenz, Angew. Chem., Int. Ed., 2009, 48, 3529-3531.

169 C. Wang, M. F. Chi, D. G. Li, D. Strmenik, D. van der Vliett, G. F. Wang, V. Komanicky, K. C. Chang, A. P. Paulikas, D. Tripkovic, J. Pearson, K. L. More, N. M. Markovic and V. R. Stamenkovic, J. Am. Chem. Soc., 2011, 133, 14396-14403.

170 C. Wang, H. Daimon, T. Onodera, T. Koda and S. Sun, Angew. Chem., Int. Ed., 2008, 47, 3588-3591.

171 J. Zhang, H. Yang, J. Fang and S. Zou, Nano Lett., 2010, 10, 638644

172 J. Wu, J. Zhang, Z. Peng, S. Yang, F. T. Wagner and H. Yang, J. Am. Chem. Soc., 2010, 132, 4984-4985.

173 J. Wu, A. Gross and H. Yang, Nano Lett., 2011, 11, 798-802.

174 C. M. Sanchez-Sanchez, J. Solla-Gullon, F. J. Vidal-Iglesias, A. Aldaz, V. Montiel and E. Herrero, J. Am. Chem. Soc., 2010, 132, 5622 .

175 S. Koh and P. Strasser, J. Am. Chem. Soc., 2007, 129, 12624 12625 
176 B. Lim, M. Jiang, P. H. C. Camargo, E. C. Cho, J. Tao, X. Lu, Y. Zhu and Y. Xia, Science, 2009, 324, 1302-1305.

177 J. X. Wang, H. Inada, L. J. Wu, Y. M. Zhu, Y. M. Choi, P. Liu, W. P. Zhou and R. R. Adzic, J. Am. Chem. Soc., 2009, 131, 17298-17302.

178 D. L. Wang, H. L. Xin, Y. C. Yu, H. S. Wang, E. Rus, D. A. Muller and H. D. Abruna, J. Am. Chem. Soc., 2010, 132, 17664-17666.

179 C. Wang, D. van der Vliet, K. L. More, N. J. Zaluzec, S. Peng, S. H. Sun, H. Daimon, G. F. Wang, J. Greeley, J. Pearson, A. P. Paulikas, G. Karapetrov, D. Strmcnik, N. M. Markovic and V. R. Stamenkovic, Nano Lett., 2011, 11, 919-926.

180 K. P. Gong, D. Su and R. R. Adzic, J. Am. Chem. Soc., 2010, 132 $14364-14366$.

181 K. Sasaki, H. Naohara, Y. Cai, Y. M. Choi, P. Liu, M. B. Vukmirovic, J. X. Wang and R. R. Adzic, Angew. Chem., Int. Ed., 2010, 49, 8602-8607.

182 Engelhard Industrial Bullion Prices, http://apps.catalysts.basf.com/ apps/eibprices/mp/, accessed 31 October, 2011.

183 J. X. Wang, C. Ma, Y. Choi, D. Su, Y. Zhu, P. Liu, R. Si, M. B. Vukmirovic, Y. Zhang and R. R. Adzic, J. Am. Chem. Soc., 2011, 133, 13551-13557.

184 Z. H. Gu and P. B. Balbuena, J. Phys. Chem. C, 2008, 112, 50575065.

185 S. C. Ball, S. L. Burton, J. Fisher, R. O'Malley, B. C. Tessier, B. Theobald, D. Thompsett, W.-P. Zhou, D. Su, Y. Zhu and R. Adzic, ECS Trans., 2009, 25, 1023-1036.

186 D. V. Esposito and J. G. G. Chen, Energy Environ. Sci., 2011, 4, 3900-3912.

187 I. E. L. Stephens and I. Chorkendorff, Angew. Chem., Int. Ed., 2011, 50, 1476-1477.

188 D. V. Esposito, S. T. Hunt, A. L. Stottlemyer, K. D. Dobson, B. E. McCandless, R. W. Birkmire and J. G. G. Chen, Angew. Chem., Int. Ed., 2010, 49, 9859-9862.

189 L. Vitos, A. V. Ruban, H. L. Skriver and J. Kollar, Surf. Sci., 1998, 411, 186-202.

190 A. Vojvodic, C. Ruberto and B. I. Lundqvist, J. Phys.: Condens. Matter, 2010, 22, 375504

191 D. J. Mowbray, J. I. Martinez, F. Calle-Vallejo, J. Rossmeisl K. S. Thygesen, K. W. Jacobsen and J. K. Norskov, J. Phys. Chem. C, 2011, 115, 2244-2252.
192 D. Friebel, D. J. Miller, D. Nordlund, H. Ogasawara and A. Nilsson, Angew. Chem., Int. Ed., 2011, 50, 10190-10192.

193 G. H. Johannesson, T. Bligaard, A. V. Ruban, H. L. Skriver, K. W. Jacobsen and J. K. Nørskov, Phys. Rev. Lett., 2002, 88, 255506.

194 T. Bligaard, G. H. Johannesson, A. V. Ruban, H. L. Skriver, K. W. Jacobsen and J. K. Nørskov, Appl. Phys. Lett., 2003, 83, 4527-4529.

195 S. Jong Yoo, S.-K. Kim, T.-Y. Jeon, S. Jun Hwang, J.-G. Lee, S.-C. Lee, K.-S. Lee, Y.-H. Cho, Y.-E. Sung and T.-H. Lim, Chem. Commun., 2011, 47, 11414-11416.

196 J. H. Westbrook and R. L. Fleischer, Intermetallic Compounds: Principles and Practise, 1994.

197 U. A. Paulus, A. Wokaun, G. G. Scherer, T. J. Schmidt, V. Stamenkovic, N. M. Markovic and P. N. Ross, Electrochim. Acta, 2002, 47, 3787-3798.

198 B. Cordero, V. Gomez, A. E. Platero-Prats, M. Reves, J. Echeverria, E. Cremades, F. Barragan and S. Alvarez, Dalton Trans., 2008, $2832-2838$.

199 H. Okamoto, J. Phase Equilib. Diffus., 2008, 29, 122.

200 C. H. Kjaergaard, J. Rossmeisl and J. K. Nørskov, Inorg. Chem., 2010, 49, 3567-3572

201 A. S. Bondarenko and G. A. Ragoisha, in Progress in Chemometrics Research, Nova Sci. Publishers, New York, 2005, pp. 89-102.

202 P. E. Blochl, C. J. Forst and J. Schimpl, Bull. Mater. Sci., 2003, 26, 33-41.

203 B. Hammer, L. B. Hansen and J. K. Norskov, Phys. Rev. B: Condens. Matter Mater. Phys., 1999, 59, 7413-7421.

204 Atomic Simulation Environment, https://wiki.fysik.dtu.dk/ase, accessed 14 December, 2011.

205 J. J. Mortensen, L. B. Hansen and K. W. Jacobsen, Phys. Rev. B: Condens. Matter Mater. Phys., 2005, 71, 035109.

206 H. Ogasawara, B. Brena, D. Nordlund, M. Nyberg, A. Pelmenschikov, L. G. M. Pettersson and A. Nilsson, Phys. Rev. Lett., 2002, 89, 276102.

207 T. Schiros, L. A. Naslund, K. Andersson, J. Gyllenpalm, G. S. Karlberg, M. Odelius, H. Ogasawara, L. G. M. Pettersson and A. Nilsson, J. Phys. Chem. C, 2007, 111, 15003-15012.

208 A. Michaelides and P. Hu, J. Chem. Phys., 2001, 114, 513-519.

209 P. J. Feibelman, Science, 2002, 295, 99-102.

210 C. Clay, S. Haq and A. Hodgson, Phys. Rev. Lett., 2004, 92, 046102. 